\title{
43. PALEOMAGNETISM OF BASALTS, LEG 34
}

\author{
James M. Ade-Hall and Harlan Paul Johnson, Department of Geology, \\ Dalhousie University, Halifax, Nova Scotia, Canada
}

\section{INTRODUCTION}

Leg 34 of the Deep Sea Drilling Project was the first to have deep basement penetration as a major objective. Because of bad formation conditions at the three sites occupied in the Nazca plate, the cumulative basement penetration was only 105 meters with 15 meters (14\%) recovery. At all sites the recovered basement rocks were basalts. A total of 34 samples was taken for shipboard paleomagnetic study. Natural remanence moments were measured and alternating field demagnetized from 50 to 200 oe peak field. Further demagnetization steps were carried out at Dalhousie University. Other shore investigations reported here are the NRMs of a small set of Leg 16 basalts. The latter are from the southern flank of the Carnegie Ridge, which may form a part of the Nazca plate, and are described here as the NRM directions that may have a bearing on the motion of the Nazca plate as a whole.

\section{EXPERIMENTAL METHOD}

The shipboard paleomagnetic laboratory consisted of a Schonstedt SSM1 - a spinner magnetometer and an alternating field demagnetizing unit. The latter consisted of a two-axis tumbler within hemispherical demagnetizing coils, supplied by a $480-\mathrm{Hz}$ motor-generator unit, the whole system being enclosed within a set of six concentric permalloy shields. A MS3 susceptibility bridge and a Schonstedt DM 2200 portable laboratory fluxgate magnetometer completed the shipboard facility. Shipboard data reduction was carried out using the PDP-8 computer forming part of the satellite navigation system.

Samples for paleomagnetic study were partly oriented, only the sense of the vertical axis being known. An attempt to take a fully oriented core, using a Sperry Sun magnetic compass core orientation tool, failed.

On recovery, segments of the main core, which clearly had not tumbled in the core liner, were marked with a vertical line exactly parallel to the core axis. This reference line, of unknown azimuth, was extended from one segment of core to the next when a convincing fit of the pieces was evident. The usefulness of this reference line is in making within-unit or between-unit comparisons of the direction of the horizontal NRM component. These features may be important for polarity determination for low magnetic inclination samples and in proving the original cooling nature of NRM on grounds of within-unit directional consistency. Oneinch-diameter cores were then drilled transversely through the main core, with the reference line as a diameter, and the orientation information was transcribed from the main core to the transverse core ("minicore") as shown in Figure 1. The transverse core

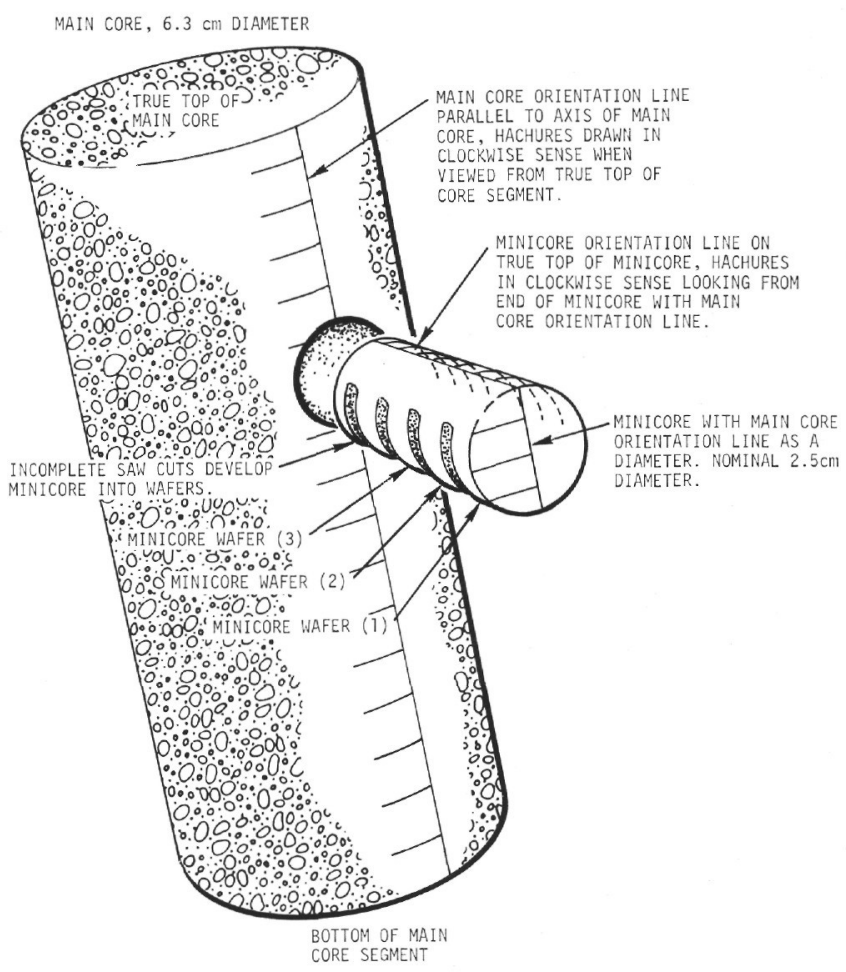

Figure 1. Paleomagnetic orientation and sampling convention.

was then sliced into several measurement slices ("minicore wafers") for paleomagnetic, geochemical, and other tests. Wafers for paleomagnetic work were from 1.5 to $2.0 \mathrm{~cm}$ long, typical volumes and masses were $7 \mathrm{cc}$ and $20 \mathrm{~g}$ respectively. Because of the relatively high magnetic intensity of the submarine basalts, these small samples were sufficient for precise measurement, even after demagnetization at high fields.

The shipboard paleomagnetic laboratory was used to measure the undemagnetized NRM of samples and the values after demagnetization at peak fields from 50 oe to 200 oe. Further demagnetization steps were carried out at Dalhousie University, together with a range of other measurements. These measurements were made using a Schonstedt DSM-1 unit, consisting of spinner magnetometer interfaced with a PDP-11 computer, together with an alternating field demagnetizer capable of reaching peak fields of 1300 oe.

\section{RESULTS}

\section{Cleaned NRM Directions}

Tables 1 and 2 list the results of the measurement of the NRM of Leg 34 and Leg 16 samples after demagnetization to peak fields from 100 oe to 1100 oe. 
TABLE 1

Paleomagnetic Directions, Initial Susceptibilities, $Q$ Ratios, and Mean Demagnetization Fields for Leg 34 Basalt Samples

\begin{tabular}{|c|c|c|c|c|c|c|c|c|}
\hline $\begin{array}{c}\text { Sample } \\
\text { (Interval in } \mathrm{cm} \text { ) }\end{array}$ & $\begin{array}{l}\text { Sample } \\
\text { Demagneti- } \\
\text { zation } \\
\text { field a }\end{array}$ & $J^{\mathrm{b}}$ & $\phi^{\mathrm{c}}$ & $I^{\mathrm{d}}$ & & $k^{\mathrm{e}}$ & $Q^{\mathrm{f}}$ & $\mathrm{MDF}^{\mathrm{g}}$ \\
\hline \multicolumn{9}{|c|}{ Unit 1} \\
\hline $319-13-1,75-78(2)$ & $\begin{array}{l}000 \\
050 \\
100 \\
250 \\
300 \\
350 \\
400\end{array}$ & $\begin{array}{l}1.81 \\
1.78 \\
1.59 \\
0.798 \\
0.343 \\
0.198 \\
0.196\end{array}$ & $\begin{array}{l}024 \\
024 \\
027 \\
057 \\
043 \\
030 \\
032\end{array}$ & $\left.\begin{array}{l}+52 \\
+50 \\
+48 \\
+59 \\
+47 \\
+61 \\
+50\end{array}\right\}$ & +53 & 2.1 & $2.9(2.9)^{\mathrm{h}}$ & $230(230)^{\mathrm{i}}$ \\
\hline \multicolumn{9}{|c|}{ (Anhysteritic magnetization induced during alternating demagnetization tests at $150,200,500,600$, and 700 oe) } \\
\hline 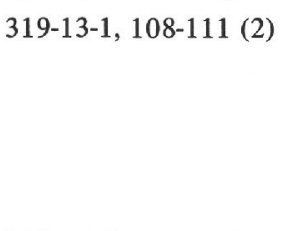 & $\begin{array}{l}000 \\
050 \\
100 \\
200 \\
250 \\
300 \\
350\end{array}$ & $\begin{array}{l}1.62 \\
1.61 \\
1.47 \\
1.23 \\
0.706 \\
0.517 \\
0.499\end{array}$ & $\begin{array}{l}087 \\
085 \\
084 \\
061 \\
068 \\
076 \\
094\end{array}$ & $\left.\begin{array}{l}+47 \\
+47 \\
+44 \\
+56 \\
+28 \\
+39 \\
+50\end{array}\right\}$ & +44 & 1.8 & $3.0(3.0)$ & 更 \\
\hline 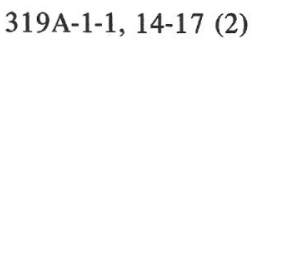 & $\begin{array}{l}000 \\
050 \\
200 \\
250 \\
300 \\
350 \\
400 \\
500\end{array}$ & $\begin{array}{l}3.44 \\
3.44 \\
2.44 \\
1.54 \\
0.895 \\
0.683 \\
0.462 \\
0.222\end{array}$ & $\begin{array}{l}323 \\
323 \\
022 \\
029 \\
029 \\
040 \\
040 \\
061\end{array}$ & $\begin{array}{l}+30 \\
+30 \\
-23 \\
-11 \\
+03 \\
+25 \\
+25 \\
+52\end{array}$ & $\begin{array}{l}\text { No } \\
\text { cleaned } \\
\text { inclination } \\
\text { identified }\end{array}$ & 2.1 & $5.5(5.8)$ & 240 (indet.) \\
\hline $319 \mathrm{~A}-1-1,39-42(2)$ & $\begin{array}{l}000 \\
050 \\
100 \\
200 \\
250 \\
300 \\
350 \\
400\end{array}$ & $\begin{array}{l}4.43 \\
3.28 \\
3.30 \\
1.30 \\
1.20 \\
0.976 \\
0.737 \\
0.514\end{array}$ & $\begin{array}{l}181 \\
187 \\
202 \\
182 \\
186 \\
204 \\
188 \\
170\end{array}$ & $\left.\begin{array}{r}-25 \\
-09 \\
.00 \\
+29 \\
+33 \\
+41 \\
+33 \\
+40\end{array}\right\}$ & +38 & 2.0 & $7.4(9.6)$ & $125,(89)$ \\
\hline \multicolumn{9}{|c|}{ Unit 4} \\
\hline $319-2-1,106-109$ (2) & $\begin{array}{l}000 \\
050 \\
100 \\
167 \\
200 \\
250 \\
300 \\
350 \\
400\end{array}$ & $\begin{array}{l}5.16 \\
4.91 \\
5.02 \\
3.25 \\
2.76 \\
2.29 \\
1.84 \\
1.57 \\
0.881\end{array}$ & $\begin{array}{l}223 \\
232 \\
232 \\
233 \\
263 \\
255 \\
258 \\
249 \\
231\end{array}$ & $\left.\begin{array}{l}+18 \\
+35 \\
+64 \\
+59 \\
+71 \\
+65 \\
+66 \\
+67 \\
+77\end{array}\right\}$ & +66 & 1.6 & $11(20)$ & $220(105)$ \\
\hline $319 A-2-1,146-149$ (2) & $\begin{array}{l}000 \\
050 \\
100 \\
200 \\
250 \\
300 \\
350 \\
400 \\
450 \\
500 \\
600 \\
700\end{array}$ & $\begin{array}{c}19.4 \\
21.3 \\
15.3 \\
7.14 \\
4.49 \\
3.18 \\
2.35 \\
1.90 \\
1.49 \\
1.05 \\
0.71 \\
0.59\end{array}$ & $\begin{array}{c}269 \\
277 \\
283 \\
290 \\
289 \\
294 \\
282 \\
298 \\
281 \\
294 \\
298 \\
290\end{array}$ & $\left.\begin{array}{l}+46 \\
+52 \\
+51 \\
+55 \\
+59 \\
+62 \\
+54 \\
+52 \\
+48 \\
+66 \\
+66 \\
+44\end{array}\right\}$ & +55 & 7.7 & $8.4(9.2)$ & $160(150)$ \\
\hline $319 A-3-2,108-111$ (2) & $\begin{array}{l}000 \\
050 \\
100 \\
167 \\
200 \\
250 \\
300 \\
350 \\
400\end{array}$ & $\begin{array}{r}16.5 \\
12.7 \\
8.31 \\
3.69 \\
3.04 \\
2.15 \\
1.45 \\
2.09 \\
1.53\end{array}$ & $\begin{array}{l}172 \\
171 \\
184 \\
151 \\
149 \\
173 \\
165 \\
213 \\
176\end{array}$ & $\begin{array}{l}-57 \\
-51 \\
-26 \\
-02 \\
+26 \\
+08 \\
+11 \\
+37 \\
+19\end{array}$ & $\begin{array}{l}\text { No } \\
\text { cleaned } \\
\text { inclination } \\
\text { identified }\end{array}$ & 2.0 & $28(28)$ & $100(95)$ \\
\hline
\end{tabular}


TABLE 1 - Continued

\begin{tabular}{|c|c|c|c|c|c|c|c|c|}
\hline $\begin{array}{c}\text { Sample } \\
\text { (Interval in } \mathrm{cm} \text { ) }\end{array}$ & $\begin{array}{c}\text { Sample } \\
\text { Demagneti- } \\
\text { zation } \\
\text { field }^{\text {a }}\end{array}$ & $J^{\mathrm{b}}$ & $\phi^{\mathrm{c}}$ & $I^{\mathrm{d}}$ & & $k^{\mathrm{e}}$ & $Q^{\mathrm{f}}$ & $\mathrm{MDF}^{\mathrm{g}}$ \\
\hline \multirow[t]{9}{*}{$319 A-3-5,81-84$ (2) } & 000 & 19.8 & 210 & -34 & & 28.6 & $2.3(3.6)$ & $55(40)$ \\
\hline & 050 & 10.6 & 233 & +48 & & & & \\
\hline & 100 & 4.92 & 234 & $+77)$ & & & & \\
\hline & 115 & 3.79 & 243 & +56 & & & & \\
\hline & 150 & 1.60 & 249 & +63 & & & & \\
\hline & 200 & 1.18 & 255 & $+51\}$ & +61 & & & \\
\hline & 250 & 0.98 & 211 & +66 & & & & \\
\hline & 300 & 0.66 & 175 & +51 & & & & \\
\hline & 350 & 0.42 & 258 & +65 & & & & \\
\hline \multicolumn{9}{|c|}{ Unit 6} \\
\hline \multirow[t]{9}{*}{$319 A-4-1,133-136(2)$} & 000 & 71.8 & 143 & -63 & & 16.7 & $14(14)$ & $210(25)$ \\
\hline & 050 & 11.5 & 130 & +21 & & & & \\
\hline & 100 & 8.94 & 120 & $+62)$ & & & & \\
\hline & 150 & 5.27 & 121 & +66 & & & & \\
\hline & 200 & 4.12 & 121 & +65 & & & & \\
\hline & 250 & 2.87 & 111 & +61 & +64 & & & \\
\hline & 300 & 2.06 & 130 & +64 & & & & \\
\hline & 350 & 1.54 & 146 & +73 & & & & \\
\hline & 400 & 0.87 & 095 & $+55]$ & & & & \\
\hline \multirow{8}{*}{ 319A-4-1, 141-144 (2) } & 000 & 60.1 & 162 & -56 & & 16.3 & $12(12)$ & $? 10(35)$ \\
\hline & 050 & 13.3 & 130 & +22 & & & & \\
\hline & $\begin{array}{l}100 \\
150^{\alpha}\end{array}$ & $\begin{array}{r}10.7 \\
6.28\end{array}$ & $\begin{array}{l}125 \\
115\end{array}$ & $\begin{array}{l}+54 \\
+57\end{array}$ & & & & \\
\hline & 200 & 3.90 & 120 & $+61\}$ & +58 & & & \\
\hline & 250 & 3.39 & 110 & +56 & & & & \\
\hline & 300 & 1.92 & 104 & $+62]$ & & & & \\
\hline & 350 & 2.15 & 104 & +57 & & & & \\
\hline & 400 & 1.43 & 144 & +59 & & & & \\
\hline \multirow[t]{12}{*}{$319 A-5-1,72-75(2)$} & 000 & 40.6 & 165 & -18 & & 21.8 & $6.2(12)$ & $70(20)$ \\
\hline & 050 & 23.7 & 169 & +56 & & & & \\
\hline & 100 & 16.8 & 171 & $+59)$ & & & & \\
\hline & 150 & 10.1 & 168 & +59 & & & & \\
\hline & 200 & 7.42 & 175 & +63 & & & & \\
\hline & 250 & 4.96 & 169 & +61 & & & & \\
\hline & 300 & 4.00 & 176 & $+61\}$ & +60 & & & \\
\hline & 350 & 3.27 & 189 & +61 & & & & \\
\hline & 400 & 1.95 & 166 & +59 & & & & \\
\hline & 500 & 1.15 & 191 & +59 & & & & \\
\hline & 600 & 0.93 & 178 & +60 J & & & & \\
\hline & 700 & 0.59 & 164 & +71 & & & & \\
\hline \multirow[t]{10}{*}{$319 A-5-1,87-90(2)$} & 000 & 45.1 & 172 & -23 & & 23.1 & $6.5(13)$ & $25(15)$ \\
\hline & 050 & 15.9 & 159 & +32 & & & & \\
\hline & 100 & 10.9 & 153 & +46 & & & & \\
\hline & 150 & 6.02 & 190 & $+62)$ & & & & \\
\hline & 200 & 4.71 & 157 & +58 & & & & \\
\hline & 250 & 3.30 & 150 & +53 & & & & \\
\hline & 300 & 2.52 & 145 & $+62\}$ & +57 & & & \\
\hline & 350 & 1.77 & 164 & +55 & & & & \\
\hline & 400 & 1.47 & 150 & $+52]$ & & & & \\
\hline & 500 & 0.617 & 165 & +68 & & & & \\
\hline \multicolumn{9}{|c|}{ Unit 7} \\
\hline \multirow[t]{11}{*}{$319 A-6-1,142-145$ (2) } & 000 & 19.3 & 033 & $+74(+67)$ & \multirow{11}{*}{+66} & 1.8 & $36(36)$ & $410(410)$ \\
\hline & 050 & 19.8 & 032 & $+74(+67)$ & & & & \\
\hline & 100 & 19.4 & 032 & $+73(+66)$ & & & & \\
\hline & 150 & 18.5 & 029 & $+76(+69)$ & & & & \\
\hline & 200 & 18.6 & 039 & $+74(+67)$ & & & & \\
\hline & 250 & 16.5 & 041 & $+73(+66)$ & & & & \\
\hline & 300 & 14.0 & 043 & $+74(+67)$ & & & & \\
\hline & 350 & 12.3 & 042 & $+72(+65)$ & & & & \\
\hline & 400 & 10.3 & 045 & $+72(+65)$ & & & & \\
\hline & 500 & 7.92 & 044 & $+69(+62)$ & & & & \\
\hline & 600 & 5.05 & 048 & $+70(+63)$ & & & & \\
\hline
\end{tabular}


TABLE 1 - Continued

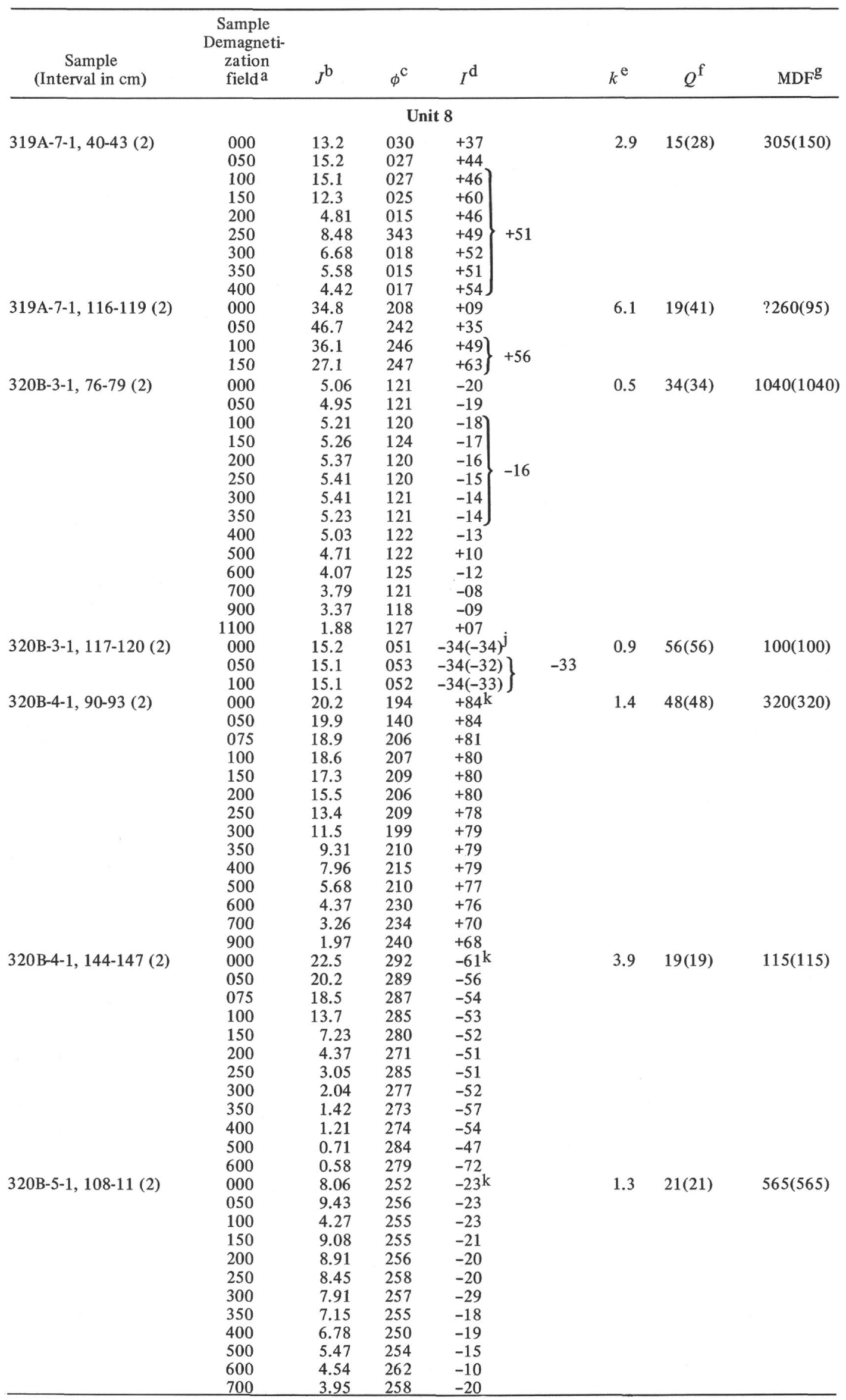


TABLE 1 - Continued

\begin{tabular}{|c|c|c|c|c|c|c|c|c|}
\hline $\begin{array}{c}\text { Sample } \\
\text { (Interval in } \mathrm{cm} \text { ) }\end{array}$ & $\begin{array}{l}\text { Sample } \\
\text { Demagneti- } \\
\text { zation } \\
\text { field }^{\mathrm{a}}\end{array}$ & $J^{\mathrm{b}}$ & $\phi^{\mathrm{c}}$ & $I^{\mathrm{d}}$ & & $k^{\mathrm{e}}$ & $Q^{\mathrm{f}}$ & $\mathrm{MDF}^{\mathrm{g}}$ \\
\hline \multirow[t]{12}{*}{ 320B-5, bit sample (2) } & 000 & 7.93 & 066 & $+41^{\mathrm{k}}$ & & 0.5 & $53(53)$ & $415(415)$ \\
\hline & 050 & 8.11 & 065 & +41 & & & & \\
\hline & 100 & 7.75 & 065 & +41 & & & & \\
\hline & 150 & 7.26 & 065 & +42 & & & & \\
\hline & 200 & 6.69 & 065 & +42 & & & & \\
\hline & 250 & 6.15 & 066 & +42 & & & & \\
\hline & 300 & 5.54 & 067 & +42 & & & & \\
\hline & 350 & 4.65 & 066 & +43 & & & & \\
\hline & 400 & 4.17 & 067 & +43 & & & & \\
\hline & 500 & 3.22 & 066 & +45 & & & & \\
\hline & 600 & 2.69 & 067 & +43 & & & & \\
\hline & 700 & 1.93 & 066 & +46 & & & & \\
\hline \multirow[t]{9}{*}{$321-13-4,91-94(2)$} & 000 & 13.0 & 057 & +24 & & 9.7 & 45 & $265(265)$ \\
\hline & 050 & 13.0 & 055 & +23 & & & & \\
\hline & 100 & 12.2 & 055 & +23 & & & & \\
\hline & 150 & 11.7 & 054 & $+22\}$ & & & & \\
\hline & 200 & 9.80 & 053 & +22 & +22 & & & \\
\hline & 250 & 7.22 & 054 & +21 & & & & \\
\hline & 300 & 5.21 & 055 & +19 & & & & \\
\hline & 400 & 3.33 & 056 & +31 & & & & \\
\hline & 450 & 1.95 & 042 & +11 & & & & \\
\hline \multicolumn{9}{|c|}{ Unit 2} \\
\hline \multirow[t]{4}{*}{$321-13-4,142-145$ (2) } & 000 & 3.90 & 207 & -25 & & 11.3 & 1.1 & Indet. \\
\hline & 050 & 4.02 & 204 & -25 & & & & \\
\hline & 075 & 3.88 & 205 & $-21)$ & 22 & & & \\
\hline & 100 & 3.26 & 205 & $-22\}$ & -22 & & & \\
\hline \multicolumn{9}{|c|}{ Unit 3} \\
\hline \multirow[t]{13}{*}{$321-14-1,58-61(2)$} & 000 & 83.5 & 340 & -05 & & 31.3 & $>5.4$ & $<105$ \\
\hline & 050 & 77.2 & 346 & -08 & & & & \\
\hline & 100 & 45.5 & 343 & -11 & & & & \\
\hline & 150 & 24.8 & 343 & -02 & & & & \\
\hline & 250 & 15.8 & 340 & -10 ) & & & & \\
\hline & 300 & 10.9 & 341 & -08 & & & & \\
\hline & 350 & 8.32 & 341 & -08 & -08 & & & \\
\hline & 400 & 6.90 & 344 & -08 & & & & \\
\hline & 500 & 4.23 & 343 & -02 & & & & \\
\hline & 600 & 3.34 & 337 & -07 & & & & \\
\hline & 700 & 2.43 & 342 & -05 & & & & \\
\hline & 800 & 2.05 & 347 & -01 & & & & \\
\hline & 900 & 1.12 & 337 & +05 & & & & \\
\hline \multirow[t]{12}{*}{$321-14-1,39-42$ (2) } & 000 & $122^{1}$ & 026 & +14 & & 43.1 & $>9.4$ & $\leqslant 65$ \\
\hline & 050 & 80.8 & +06 & & & & & \\
\hline & 075 & 47.7 & 037 & -01 & & & & \\
\hline & 100 & 28.7 & 042 & -03 & & & & \\
\hline & 150 & 13.2 & 046 & -10 & & & & \\
\hline & 200 & 8.34 & 043 & -08 & & & & \\
\hline & 250 & 6.05 & 042 & -10 & -10 & & & \\
\hline & 300 & 4.51 & 042 & -11 & & & & \\
\hline & 350 & 3.75 & 048 & -15 & & & & \\
\hline & 400 & 2.87 & 036 & -14 & & & & \\
\hline & 500 & 1.74 & 028 & -12 & & & & \\
\hline & 600 & 2.05 & 042 & +09 & & & & \\
\hline \multicolumn{9}{|c|}{ 321-14-1, 39-42 (AC demagnetization cf. split from thermal demagnetization sample) } \\
\hline & 000 & $45.0^{1}$ & 056 & +10 & & 45.9 & $3.3(13)$ & $100(65)$ \\
\hline & 050 & 55.5 & 052 & -10 & & & & \\
\hline & 075 & 34.7 & 051 & -13 & & & & \\
\hline & 100 & 22.7 & 050 & -14 & & & & \\
\hline & 150 & 11.8 & 049 & $-13\}$ & -13 & & & \\
\hline & 200 & 7.73 & 051 & -13 & & & & \\
\hline & 150 & 5.24 & 047 & -11 & & & & \\
\hline & 300 & 3.94 & 048 & -10 & & & & \\
\hline & 350 & 3.27 & 046 & -12 & & & & \\
\hline & 400 & 2.64 & 049 & -15 & & & & \\
\hline & 500 & 1.72 & 045 & -23 & & & & \\
\hline & 600 & 1.49 & 053 & +01 & & & & \\
\hline & 700 & 0.69 & 037 & -01 & & & & \\
\hline
\end{tabular}


TABLE 1 - Continued

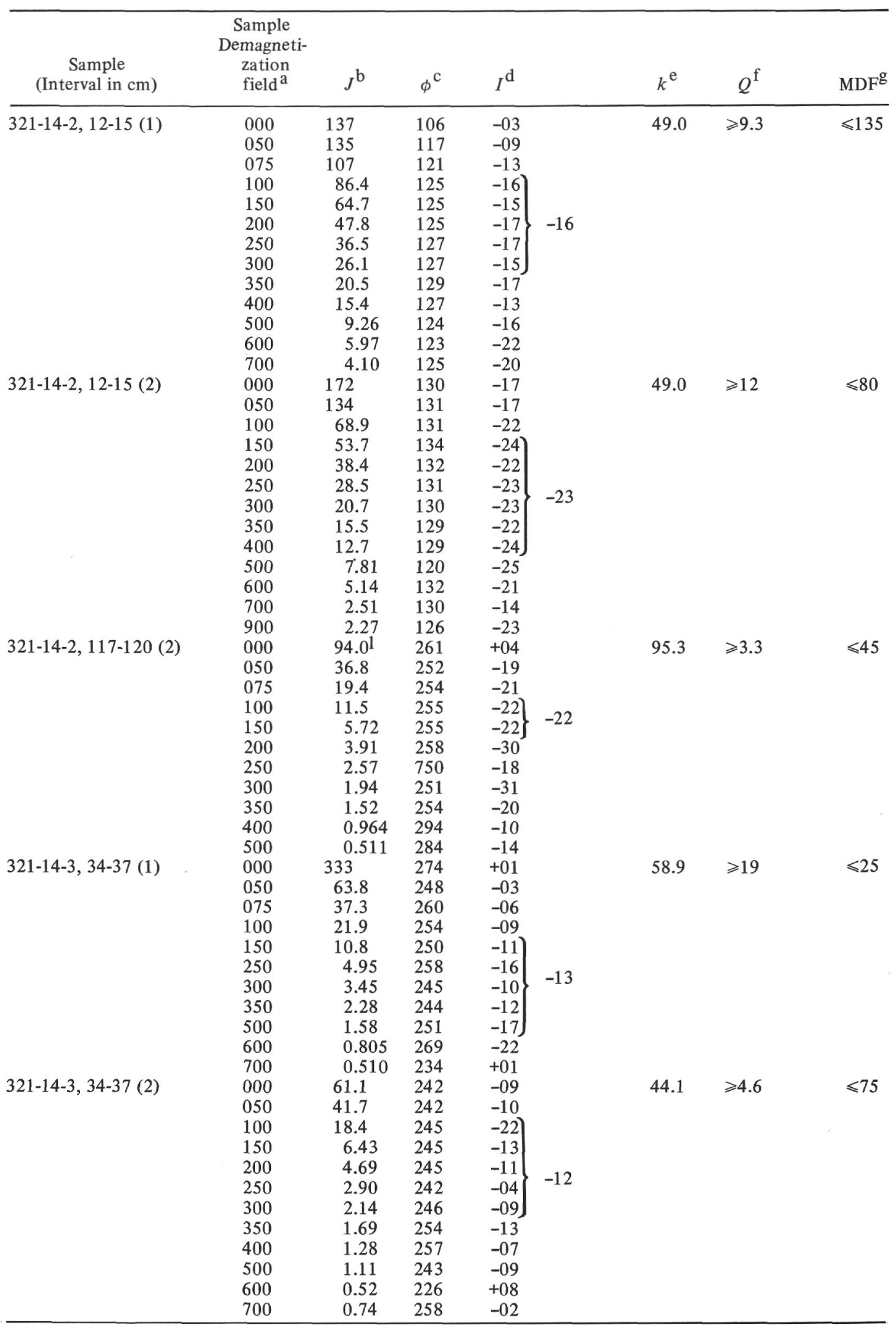

The behavior of samples during demagnetization varied widely (Figure 2). Mean demagnetization fields (MDF), a measure of NRM hardness, vary between 10 oe and 1040 oe (Figure 3). Titanomagnetite degree of oxidation and grain size are major factors in controlling MDF, with high values associated with high oxidation state and/or fine grain size and the lowest values with the unoxidized coarse-grained samples (Ade-Hall et al., Rock Magnetism of Basalts, this volume). In the undemagnetized state, or after demagnetization at low 
TABLE 1 - Continued

\begin{tabular}{|c|c|c|c|c|c|c|c|c|}
\hline $\begin{array}{c}\text { Sample } \\
\text { (Interval in } \mathrm{cm} \text { ) }\end{array}$ & $\begin{array}{l}\text { Sample } \\
\text { Demagneti- } \\
\text { zation } \\
\text { field }^{\mathrm{a}}\end{array}$ & $J^{\mathrm{b}}$ & $\phi^{\mathrm{C}}$ & $I^{\mathrm{d}}$ & & $k^{\mathrm{e}}$ & $Q^{\mathrm{f}}$ & $\mathrm{MDF}^{\mathrm{g}}$ \\
\hline \multirow[t]{13}{*}{$321-14-3,44-47(2)$} & 000 & 81.0 & 242 & +01 & \multirow{13}{*}{-19} & 65.1 & $\geqslant 4.2$ & $\leqslant 60$ \\
\hline & 050 & 46.5 & 244 & -16 & & & & \\
\hline & 075 & 28.4 & 246 & -20 ) & & & & \\
\hline & 100 & 18.7 & 244 & -19 & & & & \\
\hline & 150 & 9.87 & 245 & -21 & & & & \\
\hline & 200 & 5.22 & 241 & -16 & & & & \\
\hline & 250 & 3.75 & 245 & -20 & & & & \\
\hline & 300 & 2.77 & 251 & -20 & & & & \\
\hline & 350 & 1.44 & 254 & -25 & & & & \\
\hline & 400 & 1.26 & 231 & -12 & & & & \\
\hline & 500 & 1.03 & 231 & -17 & & & & \\
\hline & 600 & 0.902 & 249 & -10 & & & & \\
\hline & 700 & 0.665 & 270 & -51 & & & & \\
\hline \multirow[t]{11}{*}{$321-14-4,20-23(2)$} & 000 & 90.0 & 289 & -22 & \multirow{11}{*}{-19} & 121 & $\geqslant 2.5$ & $\leqslant 55$ \\
\hline & 050 & 50.7 & 293 & -22 & & & & \\
\hline & 100 & 19.7 & 286 & $-23)$ & & & & \\
\hline & 150 & 12.4 & 293 & -16 & & & & \\
\hline & 200 & 7.94 & 292 & -18 & & & & \\
\hline & 250 & 5.27 & 292 & -17 & & & & \\
\hline & 300 & 4.19 & 296 & -25 & & & & \\
\hline & 350 & 2.89 & 289 & -14 & & & & \\
\hline & 400 & 1.80 & 291 & -15 & & & & \\
\hline & 500 & 1.52 & 320 & -15 & & & & \\
\hline & 600 & 0.79 & 280 & -11 & & & & \\
\hline \multirow[t]{11}{*}{$321-14-4,45-48(2)$} & 000 & 100.0 & 007 & -01 & \multirow{11}{*}{-21} & 91.5 & $3.6(8.5)$ & $70(37)$ \\
\hline & 050 & 74.7 & 020 & -17 & & & & \\
\hline & 075 & 43.6 & 019 & -18 & & & & \\
\hline & 100 & 30.9 & 019 & $-22\}$ & & & & \\
\hline & 150 & 15.3 & 016 & -22 & & & & \\
\hline & 200 & 8.61 & 020 & -19 & & & & \\
\hline & 250 & 6.42 & 014 & -27 & & & & \\
\hline & 300 & 3.78 & 006 & -01 & & & & \\
\hline & 350 & 3.51 & 024 & -30 & & & & \\
\hline & 400 & 2.83 & 028 & +16 & & & & \\
\hline & 500 & 1.75 & 330 & -11 & & & & \\
\hline
\end{tabular}

${ }^{\mathrm{a}}$ Peak demagnetization alternating field (oe).

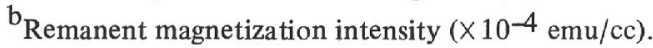

${ }^{c}$ Remanent magnetization declination with reference to arbitrary reference line marked on core $\left(^{\circ}\right)$.

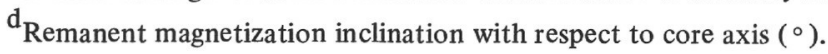

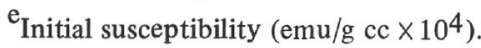
$\mathrm{f}_{\text {Konigsberger ratio of remanent to induced magnetization, } Q=\frac{J}{K F}}$ where $F$ is the ambient field, taken as 0.30 oe
for all Leg 34 sites.

$\mathrm{g}_{\text {Mean demagnetization field (oe). }}$

${ }^{\mathrm{h}} Q$ ratio using in situ magnetization estimate.

${ }^{\mathrm{i}_{\text {Corrected }}}$ using in situ magnetization estimate.

$\mathrm{j}_{\text {Bracketed values are tilt corrected. }}$

$\mathrm{k}_{\text {Unoriented sample. }}$

${ }^{1}$ First-order approximation since sample sliced before volume measured.

fields, soft remanence components were frequently present. However, with two exceptions, convincing stable NRM directions were evident at intermediate demagnetizing fields (Figure 4). At higher fields, samples acquired anhysteritic remanent magnetization (ARM) during the demagnetization process, thus obscuring the small remaining part of the NRM. The range of demagnetizing fields over which stable NRM directions were apparent are bracketed in Tables 1 and 2.
A number of arguments based on the study of subaerial lavas (e.g., Ade-Hall et al., 1971) indicate that in little altered lavas such as those being described here, cleaned NRM directions can reliably be equated with original cooling thermoremanence directions. These in turn can be equated with the direction of the ambient geomagnetic field at the time of eruption. The averages of the stable NRM directions are summarized in Table 3. Within-site inclination scatter is small for Site 319. It 
TABLE 2

Paleomagnetic Directions, Initial Susceptibilities, Q Ratios, and Mean Demagnetization Fields for Basalts From Site 157, Leg 16 (located at $01^{\circ} 45.70$ ' $\mathrm{S}, 85^{\circ} 54.17^{\prime} \mathrm{W}$ on the south flank of the Carnegie Ridge, tectonically possibly within the Nazca plate)

\begin{tabular}{|c|c|c|c|c|c|c|c|}
\hline Demagnetizing Field & $J$ & $\phi$ & \multicolumn{2}{|l|}{$I$} & $K$ & $Q$ & MDF \\
\hline \multicolumn{8}{|l|}{$49-1,136-138$} \\
\hline $\begin{array}{l}000 \\
050 \\
075 \\
100 \\
150 \\
200 \\
250 \\
300 \\
350 \\
400 \\
500\end{array}$ & $\begin{array}{c}97.5 \\
55.0 \\
32.6 \\
20.8 \\
11.1 \\
5.64 \\
3.53 \\
1.84 \\
1.50 \\
0.681 \\
0.579\end{array}$ & $\begin{array}{l}222 \\
216 \\
216 \\
218 \\
215 \\
213 \\
215 \\
218 \\
209 \\
219 \\
255\end{array}$ & $\begin{array}{l}+46 \\
+34 \\
+30 \\
+29 \\
+28 \\
+26 \\
+28 \\
+32 \\
+08 \\
+20 \\
+66\end{array}$ & +28 & 62.8 & 5.2 & 53 \\
\hline \multicolumn{8}{|l|}{$49-2,1-3$} \\
\hline $\begin{array}{l}000 \\
050 \\
075 \\
100 \\
150 \\
200 \\
250 \\
300 \\
350 \\
400 \\
500\end{array}$ & $\begin{array}{l}95.5 \\
40.1 \\
22.4 \\
13.5 \\
5.87 \\
2.55 \\
0.696 \\
0.755 \\
0.506 \\
0.190 \\
0.347\end{array}$ & $\begin{array}{l}216 \\
212 \\
210 \\
210 \\
211 \\
217 \\
218 \\
240 \\
217 \\
300 \\
064\end{array}$ & $\left.\begin{array}{l}+45 \\
+31 \\
+28 \\
+27 \\
+24\end{array}\right\}$ & +26 & 80.2 & 4.0 & 42 \\
\hline \multicolumn{8}{|l|}{$49-2,64-66$} \\
\hline $\begin{array}{l}000 \\
050 \\
075 \\
100 \\
150 \\
200 \\
250 \\
300 \\
350 \\
400 \\
500\end{array}$ & $\begin{array}{c}168 \\
51.3 \\
21.1 \\
9.66 \\
2.88 \\
1.32 \\
0.696 \\
0.823 \\
0.794 \\
0.925 \\
0.731\end{array}$ & $\begin{array}{l}115 \\
112 \\
112 \\
105 \\
113 \\
073 \\
079 \\
131 \\
044 \\
052 \\
208\end{array}$ & $\begin{array}{l}+75 \\
+64 \\
+57 \\
+53 \\
+48 \\
+30 \\
+55 \\
+23 \\
+40 \\
+49 \\
-13\end{array}$ & & $\begin{array}{r}\text { No si } \\
\text { in }\end{array}$ & $\begin{array}{l}\text { ngle cl } \\
\text { clinati } \\
\text { entifie }\end{array}$ & $\begin{array}{l}\text { ened } \\
\text { on } \\
d\end{array}$ \\
\hline \multicolumn{8}{|l|}{$49-2,135-137$} \\
\hline $\begin{array}{l}000 \\
050 \\
075 \\
100 \\
150 \\
200 \\
250 \\
300 \\
350 \\
400 \\
500 \\
600\end{array}$ & $\begin{array}{c}191 \\
148 \\
132 \\
110 \\
68.3 \\
37.1 \\
19.1 \\
9.53 \\
4.95 \\
3.17 \\
1.61 \\
1.05\end{array}$ & $\begin{array}{l}230 \\
238 \\
238 \\
238 \\
237 \\
237 \\
237 \\
236 \\
238 \\
240 \\
256 \\
272\end{array}$ & $\begin{array}{l}-48 \\
-40 \\
-36 \\
-35 \\
-35 \\
-34 \\
-35 \\
-35 \\
-33 \\
-28 \\
-32 \\
-47\end{array}$ & -35 & $\begin{array}{l}92.5 \\
(157- \\
\text { from } \\
157-4 \\
\text { shows } \\
\text { havior } \\
\text { magne } \\
-49, \mathrm{~s} \\
\text { tion: }\end{array}$ & $\begin{array}{l}9-2,1 \\
\text { ame p } \\
\text {-2, } 13 \\
\text { identi } \\
\text { durin } \\
\text { tizatio } \\
\text { able in } \\
\text { 29) }\end{array}$ & $\begin{array}{l}117 \\
29-132 \\
\text { ece as } \\
5-137 \text {; } \\
\text { cal be- } \\
\text { de- } \\
\text { n, I } \\
\text { clina- }\end{array}$ \\
\hline
\end{tabular}

is almost certain that the time interval represented by cooling units 4 to 8 at Site 319 is very short, no more than a single secular variation quasicycle on the order of $10^{3} \mathrm{yr}$, and perhaps as little as a few years if the different cooling units are the product of a single eruptive episode. A sequence of cooling units erupting over a short time interval is aptly described as a time unit, yielding a single temporally independent paleomagnetic direction (Wilson, 1970; Ade-Hall et al., 1974). The remaining cooling units from Site 319 , which are poorly represented or not represented at all by paleomagnetic data, may belong to the same time unit as cooling units 4 to 8 . At Sites 157, 320, and 321 the inclination data may be interpreted that at least two time units are represented in each basement section sampled. For Site 320 , the upwards NRM inclinations are separated by $17^{\circ}$; which is close to the limit of the range of values to be expected for a single time unit. At Sites 157 and 321 


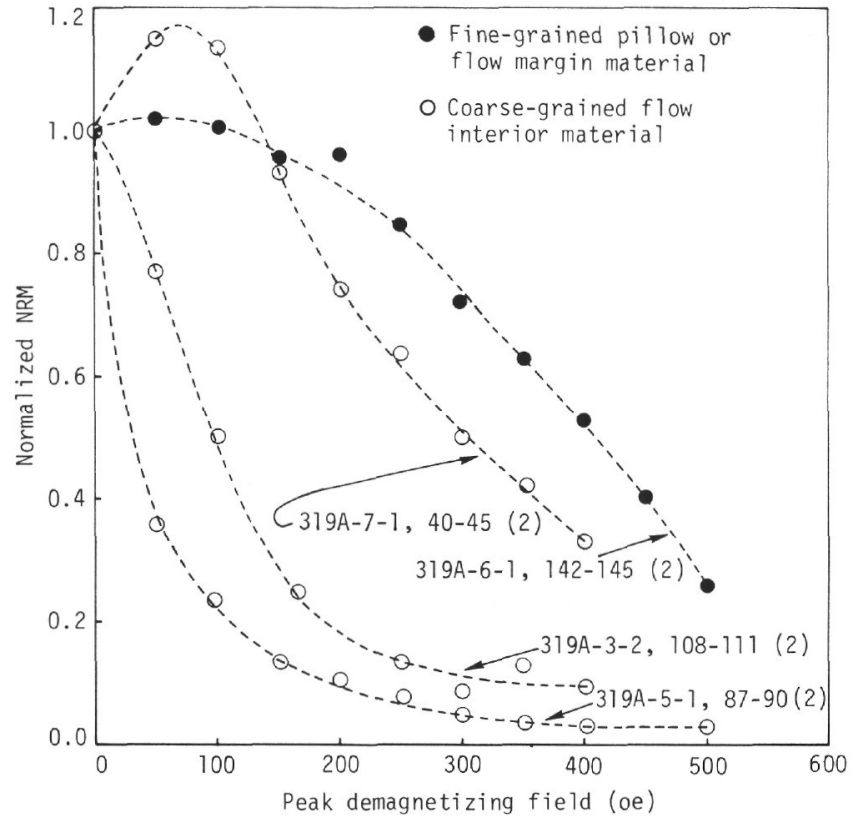

Figure 2. Normalized alternating field demagnetization curves for four basalt samples from Site 319. Mean demagnetizing field is directly related to basalt grain size at this and other sites.

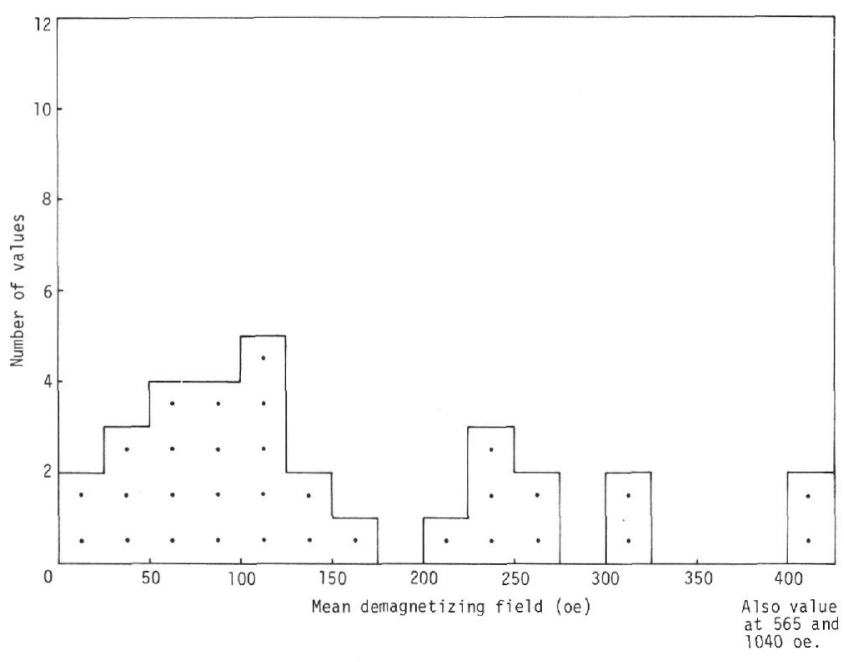

Figure 3. Histogram of mean demagnetizing field values.

single samples have inclinations of opposite sense to the remainder of the sets. Conventionally this would be evidence that a geomagnetic field reversal had been recorded by the lavas at each site. However, circumstance put doubt on this interpretation in both cases. For the Site 157 sample $(157-49-2,135-137 \mathrm{~cm})$, both stable and soft components of magnetization are reversed with respect to the other Site 157 basalts. This fact, and convincing evidence that the Site 157 basalts belong to a single lithologic unit, indicate that accidental sample inversion is the most likely explanation for the record of an apparent field reversal. For the Site 321 sample $(321-13-4,91-94 \mathrm{~cm})$ reexamination of the small, incompletely cylindrical core fragment involved indicated that the fragment had been cut by the drill bit in two or three very different orientations. This suggests that the fragment, which is too long to be rotated while in the core liner, may have been cored, and then may have fallen out of the bit and rolled over before finally entering the liner. Again accidental inversion is likely to have occurred. In summary, the evidence that more than one basement time unit was recovered from any Nazca plate site is weak.

The small number of time units represented in each basement section implies that site average NRM inclinations are unlikely to coincide with the centered axial dipole field at sites during crustal formation. That this is the case is shown by the variant indications for the apparent motion of the Nazca plate for basement NRM inclinations at each site (Table 3). The two oldest sites, 320 with an estimated basement age of 26-30 m.y. and 321 of 30-40 m.y., have cleaned NRM inclinations (basement-average) that are insignificantly different from the centered axial dipole field for the present latitude of the sites. (Basement ages are assumed to be the same as the age of the sediments lying directly on the uppermost basalt.) These imply that insignificant northsouth-directed plate motion has taken place over the time intervals since crust formation. However, the average cleaned NRM inclinations for the younger sites, 157 and 319 , are very far from centered axial dipole field values. If these differences are viewed in terms of apparent plate motions, minimum average northward velocities of 18 and $20 \mathrm{~cm} \mathrm{yr}^{-1}$ over 15 and 8 m.y., respectively, are required. In interpreting cleaned NRM inclinations, the approach adopted here is to assume that the polarities at each site are such that they minimize apparent plate motions. Even if this assumption is correct, the minimum velocity values are probably unacceptably high. It is also very difficult to believe that the plate moved rapidly to the south in the interval between $26 \mathrm{~m} . \mathrm{y}$. and $15 \mathrm{~m} . \mathrm{y}$. and then returned to its previous position at some time between 8 m.y. and the present, which must have happened if all four site-average cleaned NRM inclinations are measures of plate motion.

Support for the suggestion that the site-average NRM inclinations represent only one or two spot measurements of the geomagnetic field comes from the NRM inclinations of the overlying sediment sections. Each sediment sample represents 600 to $900 \mathrm{yr}$ and may be expected to give a good time-average measure of the geomagnetic field. For this reason the paleomagnetic field obtained from a series of sediment samples will generally be a much better measure of the centered axial dipole field at the site during deposition than will be obtained from a thick series of slightly older lavas.

Sediment site-average NRM inclinations for Sites 319,320 , and 321 are very close to the anticipated inclination for present site latitudes (see Ade-Hall and Johnson, Paleomagnetism of Sediments, this volume). This result is particularly relevant for Site 319 , where the basalt average inclination is so far from the anticipated value. It must be concluded that at least a major part of the differences between measured and anticipated NRM inclinations at Sites 157 and 319 is not the result of plate motion. Alternative explanations for the Sites 157 and 319 data are: unrepresentative sampling of the 

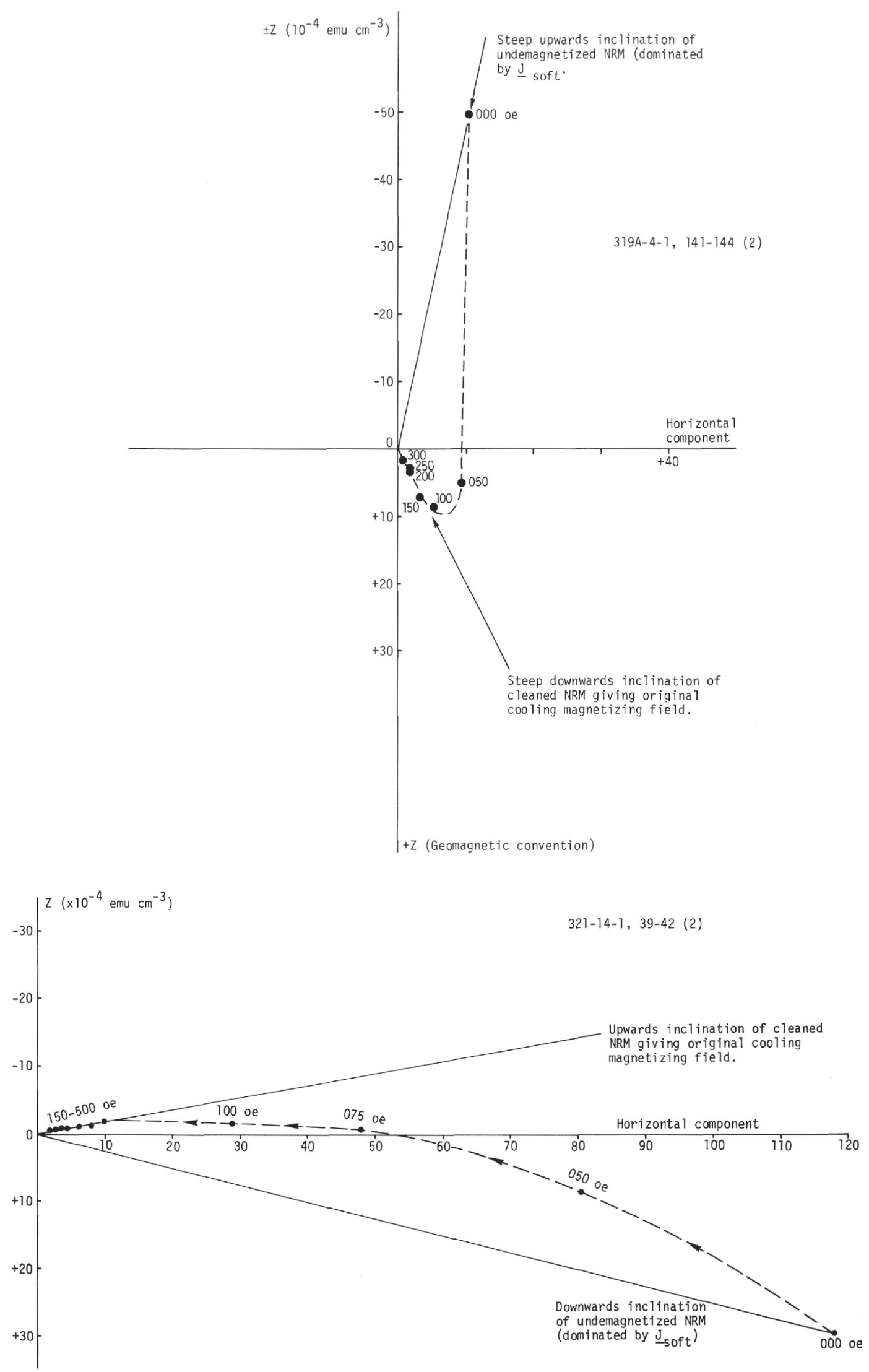

Figure 4. Behavior of NRM vector during alternating field demagnetization. 
TABLE 3

Mean Cleaned NRM Inclinations for Individual Units and Sites

\begin{tabular}{|c|c|c|c|c|}
\hline Unit & Sample Values $\left({ }^{\circ}\right)$ & & $\begin{array}{l}\text { Unit Mean Value } \\
\left( \pm \text { SD of Mean }\left[{ }^{\circ}\right]\right)\end{array}$ & $\begin{array}{c}\text { Site Mean Value } \\
\left( \pm \text { SD of Mean }\left[{ }^{\circ}\right]\right)\end{array}$ \\
\hline \multicolumn{5}{|l|}{ Hole 319} \\
\hline 1 & $+53,+44$ & $+49 \pm 5$ & & \\
\hline $\begin{array}{c}\text { Hole } 319 \mathrm{~A} \\
1\end{array}$ & +38 & +38 & & $\begin{array}{l}\text { (Anticipated cen- } \\
\text { tered axial } \\
\text { dipole inclination } \\
\text { for latitude of site) }\end{array}$ \\
\hline $\begin{array}{l}2 \\
3 \\
4 \\
5 \\
6 \\
\\
7 \\
8\end{array}$ & $\begin{array}{c}\text { No data } \\
\text { No data } \\
+66,+55,+61 \\
\text { No data } \\
+64,+58 \\
+60,+57 \\
+66,+51 \\
+56\end{array}$ & $\begin{array}{c}- \\
\overline{-} \\
+61 \pm 3 \\
- \\
+60 \pm 2 \\
+59 \pm 8 \\
+56\end{array}$ & Probably one time unit & $\begin{array}{c}+54 \pm 4 \\
(-25)\end{array}$ \\
\hline \multicolumn{5}{|l|}{ Hole 320B } \\
\hline $\begin{array}{l}\text { From separate } \\
\text { cooling units }\end{array}$ & $\begin{array}{l}-16 \\
-33\end{array}$ & $\begin{array}{l}-16 \\
-33\end{array}$ & Possibly two time units & $\begin{array}{c}-25 \pm 9 \\
(-18)\end{array}$ \\
\hline \multicolumn{5}{|l|}{ Site 321} \\
\hline $\begin{array}{l}1 \\
2 \\
3\end{array}$ & $\begin{array}{c}+22 \\
-22 \\
-08,-10,-13, \\
-16,-23,-22 \\
-13,-12,-19 \\
-19,-21\end{array}$ & $\begin{array}{l}+22 \\
-22 \\
-16 \pm 2\end{array}$ & $\begin{array}{l}\text { Almost certainly inverted } \\
\text { during drilling }\end{array}$ & $\begin{array}{c}-20 \pm 2 \\
(-23)\end{array}$ \\
\hline \multicolumn{5}{|l|}{ Site 157} \\
\hline $\begin{array}{l}\text { At least two } \\
\text { cooling units } \\
\text { time units }\end{array}$ & $\begin{array}{c}+28,+26 \\
-35\end{array}$ & $\begin{array}{c}+27 \pm 1 \\
-35\end{array}$ & $\begin{array}{c}\text { Probably inverted in core } \\
\text { laboratory }\end{array}$ & $\begin{array}{c}-31 \pm 4 \\
(-04)\end{array}$ \\
\hline
\end{tabular}

geomagnetic field, tectonic tilting of basement sections subsequent to magnetization, and partial remagnetization during a period of chemical alteration or intrusion. The evidence for unrepresentative sampling of the geomagnetic field is strong. Volcanic eruption frequency both on land (Wilson, 1970; Ade-Hall et al., 1974) and during layer 2 formation, (Melson, Aumento, et al., 1975) appears typically to be bimodal. A first attempt at defining the time scales involved (Crandell et al., 1975) suggests that sequences of flows or flow units follow one another rapidly during an interval of perhaps $500 \mathrm{yr}$ followed by a similar interval without eruption. On these grounds, the basement sections from the Nazca plate represent one, or at the most two, of the rapidly erupted sequences and do not contain information on the average geomagnetic field at the site over the whole volcanic interval.

It is difficult to assess with certainty the part played by tectonic tilting in rotating NRM vectors away from original cooling directions. Faulting is present everywhere along the Glomar Challenger Leg 34 profile across the East Pacific Rise, but appears to have resulted in insufficient block rotations to explain the observed NRM inclinations at Site 319. Clearly, however, the possibility that Sites 319 and 157 are located within small, highly rotated basement segments, unresolved by reflection profiling from the surface, cannot be excluded. Extensive directional remagnetization during halmyrolitic alteration can be set aside as an explanation in view of the unaltered state of the titanomagnetites of some massive basalts at Sites 319 and 321. Again, the close agreement between the NRM inclinations of these unaltered massive basalts and those of altered massive basalts and pillows, both of which contain cationdeficient titanomaghemites (Ade-Hall et al., Rock Magnetism of Basalts, this volume) also precludes remagnetization. Partial remagnetization as a result of the intrusions of sheets during a geomagnetic epoch of opposite polarity can be discounted on grounds of the nonrecovery of such units, together with the close within-unit agreement of cleaned NRM inclinations. Such agreement is incompatible with the steep thermal gradients and variation in degree of remagnetization, associated with the presence of minor intrusives.

\section{Soft Components in Undemagnetized NRMs}

The alternating field demagnetization of the NRM of the relatively coarse grained basalts from all sites indicated that the undemagnetized NRMs always consist of at least two components. This was evident from changes in NRM direction that occurred during demagnetization from 0 to 100 or 150 oe (Figure 4). In 
the preceding section we showed that the single NRM components remaining after demagnetization to 100 oe or 150 oe are likely to be part of the thermoremanent magnetization (TRM) acquired during initial cooling. Here, we are concerned with the nature and origin of the NRM component or components removed by demagnetization with peak fields of up to 100 oe or 150 oe. This is denoted as $J_{\text {soft }}$, the soft components of the $\mathrm{NRM}$, and the remaining magnetically hard component of the NRM as $J_{\text {hard }}$. The latter has the inclination of the geomagnetic field at the time of eruption of the basalt.

The primary interest in investigating $J_{\text {soft }}$ lies in the possibility that the polarity of $J_{\text {hard }}$ may be determined for these low magnetic latitude basalts from the geometric relationship between $J_{\text {soft }}$ and $J_{\text {hard }}$. Near the magnetic equator, the inclination of $J_{\text {hard }}$ is known to be an unreliable indicator of original TRM polarity, as shallow inclinations of both senses may be found in subaerial lava sequences of either polarity. In the absence of knowledge of the true azimuth of the often dominant horizontal component of the NRM in the Nazca plate DSDP basalts, only the geometric relationship between $J_{\text {soft }}$ and $J_{\text {hard }}$ offers a possibility for certain polarity identification. Thus, if it can be shown that $J_{\text {soft }}$ is consistent in its properties with a viscous magnetization acquired in the present field at the site, approximate parallelinity with $J_{\text {hard }}$ would imply normal polarity for the latter and opposition, reverse polarity.

We approach the problem by first identifying the properties of $J_{\text {soft }}$, as apparent from the results of alternating field demagnetization of NRMs, continue with semiquantitative attempts to separate mathematically $J_{\text {soft }}$ and $J_{\text {hard }}$ in undemagnetized NRMs, and conclude with a discussion of the prospects for the polarity identification of original TRMs for the Nazca plate basalts.

The following properties of the soft NRM components appear to be relevant to the problem:

1) $J_{\text {soft }}$ always lies within or very close to the vertical plane containing $J_{\text {hard }}$. This is evident from Figure 5 and Table 1, where it is seen that directional change during demagnetization is very largely confined to inclination change.

2) At the three Leg 34 sites, occasional initial increase in remanence intensity during demagnetization indicates that at least for these samples, $J_{\text {soft }}$ and $J_{\text {hard }}$ approximately oppose each other. This is also evident from a comparison of undemagnetized NRM inclinations and cleaned NRM inclinations for some Site 319 samples for which $J_{\text {soft }}$ is relatively very large: The former inclination before demagnetization is steeply upwards and the demagnetized NRM steeply downwards.

3 ) It is apparent from Tables 1 and 2 that $J_{\text {soft }}$ has very different inclinations at the different sites. At Site 319 it is usually if not always inclined steeply upwards. At Site 321 it is directed downwards with relatively shallow inclination. At Site 157 the vertical component of $J_{\text {soft }}$ is downwards for three samples and upwards for the fourth $(157-49-2,135-137 \mathrm{~cm})$. At Site 320 the inclination of $J_{\text {soft }}$ cannot be estimated since it only occurs in the NRM of unoriented samples. The estimates of the direction of $J_{\text {soft }}$ given above are insufficient for a full discussion of the nature and origin of these NRM components. It is desirable to know the magnitude and in-

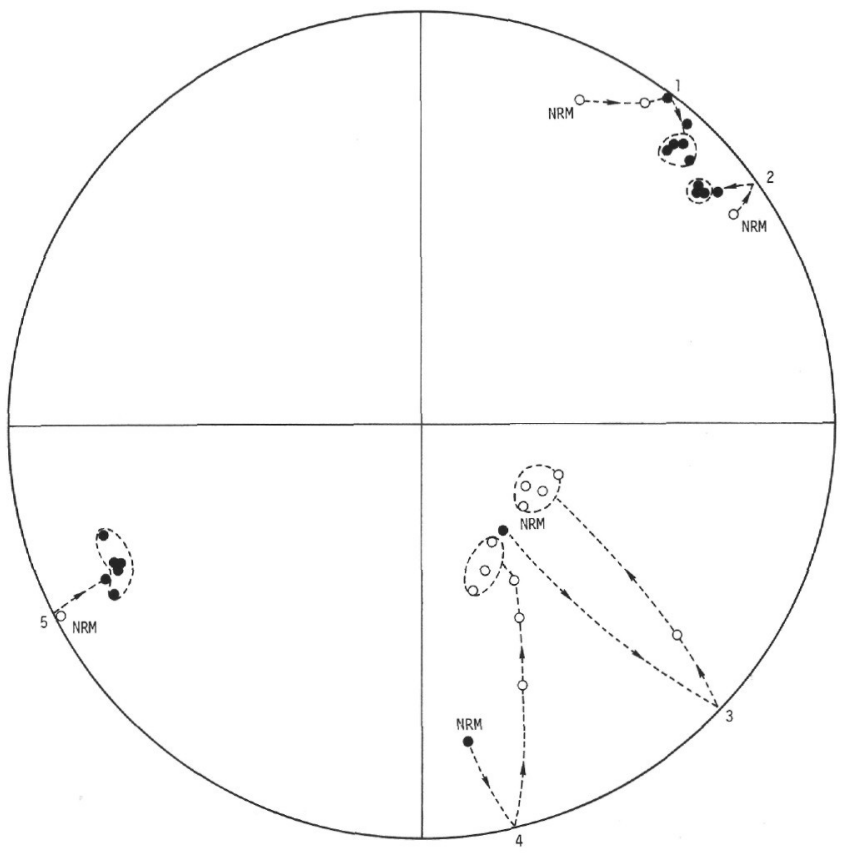

Figure 5. Stereoplot, for selected samples, of NRM directional change during demagnetization.

tensity of $J_{\text {soft }}$ in the undemagnetized NRM. Generally, it is impossible to obtain this information from the results of alternating field demagnetization alone. However, even approximate knowledge of $J_{\text {soft }}$ could be of geophysical significance. Approximate values of $J_{\text {soff }}$ can be obtained either by identifying additional restraints on the nature of $J_{\text {soft }}$ or by carrying out magnetic tests on the samples in addition to alternating field demagnetization of natural remanence.

Generally, $J_{\text {soft }}$ cannot be determined explicitly. Of the assumed minimum of two vectors, $J_{\text {soft }}$ and $J_{\text {hard }}$, comprising the undemagnetized NRM, only the direction of $J_{\text {hard }}$ is known from the results of the complete removal of $J_{\text {soft }}$ by demagnetization to high fields. The fact that $J_{\text {soft }}$ and $J_{\text {hard }}$ lie almost in the same vertical plane does not give the required extra restraint, since $J_{\text {soft }}$ could have any inclination within this plane. Only the identification of this inclination will provide the necessary extra restraint. Among the samples considered here, an approximate identification of the inclination of $J_{\text {soft }}$ can be made for a small number of the coarsest grained basalts from Hole 319A from the results of alternating field demagnetization alone. Thus, the inclinations of the undemagnetized NRMs of 319A-3-2, 108-111 cm (2); 4-1, 133-136 cm (2); and 4-1, 141-144 cm (2); at $-57^{\circ}$, $-63^{\circ}$, and $-56^{\circ}$, respectively, imply that $J_{\text {sof }}$ is inclined upwards at angles in excess of these values, which represent the resultant $J_{\text {soft }}$ and steeply downwards inclined $J_{\text {hard }}$. For these samples it will be useful to consider a simple model in which the inclination of $J_{\text {soft }}$ is assumed to be vertically upwards and to apply it to the Site 319 samples on the assumption that $J_{\text {soft }}$ has the same inclination for all samples, even where the presence of relatively small soft components does not allow confirmation of this configuration. The model is shown in Figure 6. 


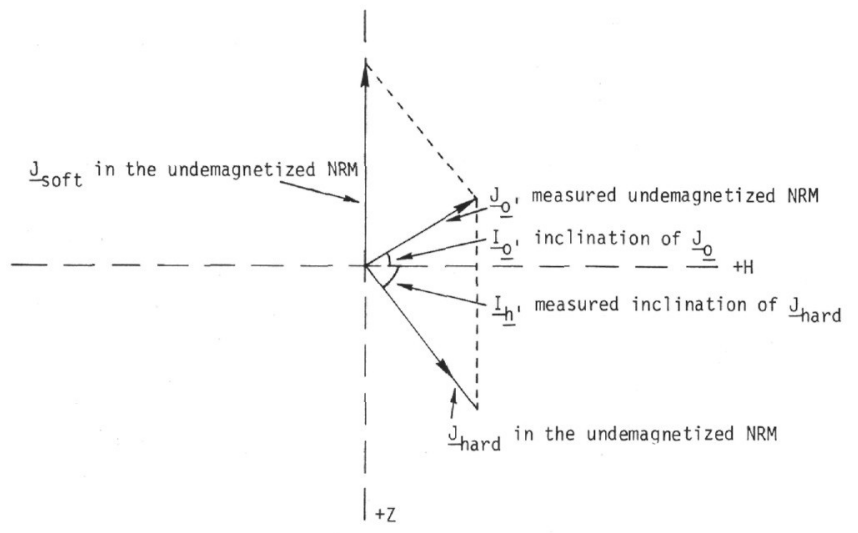

Figure 6. Vector model for a two component undemagnetized NRM with $\mathrm{J}_{\text {soft }}$ and $\mathrm{J}_{\text {hard }}$ coplanar, and $\mathrm{J}_{\text {soft }}$ oriented vertically upwards.

In this model the soft and hard components of the undemagnetized NRM are given by

and

$$
J_{\text {soft }}=J_{o} \cos I_{o}\left(\tan I_{o}-\tan I_{h}\right)
$$

$$
J_{\text {hard }}=J_{o} \cos I_{o} / \cos I_{h}
$$

Values of $J_{\text {soft }}$ and $J_{\text {hard }}$ found by this method are given in Table 4. We note that the coarsest grained basalts from Site 319 apparently can have soft components in the undemagnetized NRM that range up to nearly a factor of two stronger than hard components.

The accuracy of these results depends on how well real orientations of $J_{\text {soft }}$ fit the requirements of the simple model. To test this assumption, $J_{\text {soft }}$ in the undemagnetized NRM was determined by a second method for three of the Hole 319A basalts. The approach used was to estimate the value of undemagnetized single component NRMs for each sample, using laboratory-induced ARM as a model for the original TRM. The justification of this test is in the similarity of ARM and TRM stability (Levi, 1973; Rimbert, 1959). The samples were given ARMs in a steady field of 1.03 $G$ from a peak alternating field of 1300 oe. These ARMs were then demagnetized to 250-oe peak field and the ARM intensity at each step compared to the equivalent NRM value. It was anticipated that at high fields, where NRM consists of a single component, the ratio of ARM to NRM would be constant. The product of this ratio and the undemagnetized ARM intensity would then give values at low demagnetization fields of a single component, NRM, now represented in part only by $J_{\text {hard }}$. Only one of the ARM/NRM comparisons behaved exactly as predicted, the other two showed a gradually changing ratio, even over a range of demagnetization fields for which the NRM was clearly a single component in composition (Table 5 and Figure 7). These differences in behavior are not understood. For this test of the simple model we proceed by using all three ARM/NRM comparisons on the same basis. Figure 8 shows how $J_{\text {soft }}$ is estimated graphically for the three samples. The generally steep upwards inclination of $J_{\text {soft }}$ is confirmed. However, in no instance does $J_{\text {soft }}$ lie exactly along the vertical. Table 6 and Figure 9 summarize the results of the ARM/NRM comparison experiments.
TABLE 4

Measured Undemagnetized NRMs and Estimated Values of Soft and Hard Contributions to Undemagnetized NRMs, Site 319

\begin{tabular}{cccc}
\hline Sample & $J_{o}^{\mathrm{a}}$ & $J_{\text {soft }}^{\mathrm{a}, \mathrm{b}}$ & $J_{\text {hard }}^{\mathrm{a}, \mathrm{c}}$ \\
\hline
\end{tabular}

\section{Hole 319}

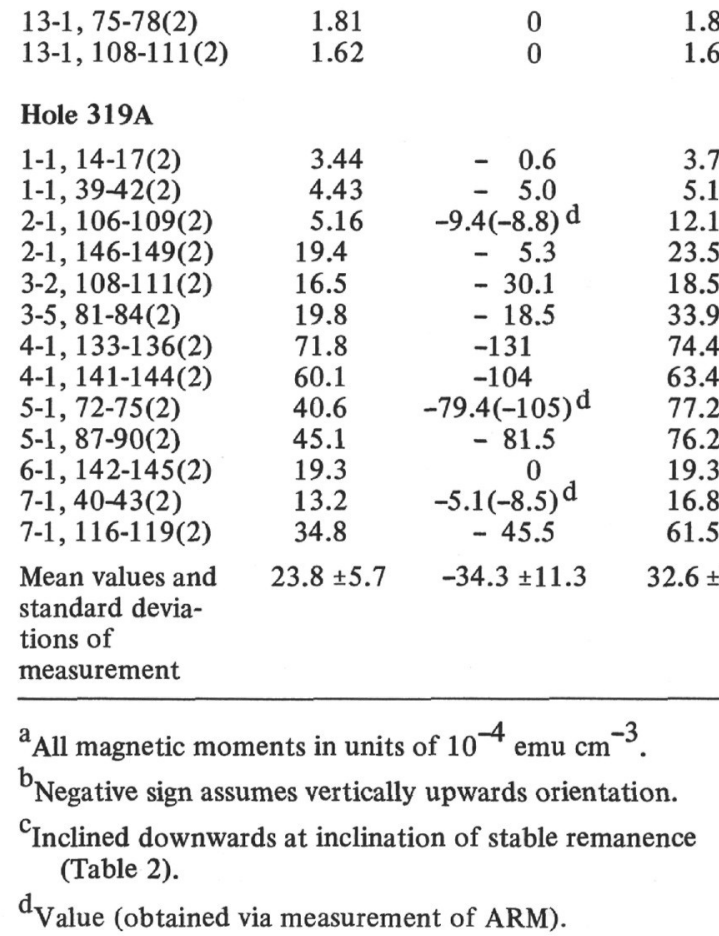

The average error from the three ARM/NRM comparisons and from the graphical model of Figure 9 is close to $-20 \%$, that is, application of the simple model underestimates $J_{\text {soft }}$ by $20 \%$ for these samples. This is an acceptable level of uncertainty for the purposes of this investigation.If $J_{\text {soft }}$ is distributed randomly within a small angular range from the vertical, for example, at not more than $15^{\circ}$ deviation, further consideration of Figure 9 shows that the average error in $J_{\text {soft }}$ determination by the simple model will be zero.

Examination of Table 1 shows that the $J_{\text {soft }}$ in undemagnetized NRMs for Site 321 basalts must have a shallow downwards inclination. This means that the simple model developed to identify $J_{\text {soft }}$ for the Site 319 basalts cannot be applied here. only the ARM/NRM comparison method can be used here, and the results of its application to two Sites 321 samples are given in Table 5. One good and one poor fit of ARM and NRM curves were obtained (Figure 10). As before, both sets of results have been used in graphical determination of $J_{\text {soft }}$ and $J_{\text {hard }}$ in the undemagnetized NRM (Figure 11). The results are summarized in Table 7 .

We note from these results that $J_{\text {soft }}$ for the coarser grained Site 321 basalts has a shallow downwards inclination and ranges up to three times the magnitude of the undemagnetized NRM.

A similar analysis could be made for the Site 157 basalts. However, the alternating field demagnetization results of Table 2 show that $J_{\text {soft }}$ has a different sense for 
TABLE 5

Comparison of NRM and ARM Intensities for Selected Leg 34 Basalt Samples

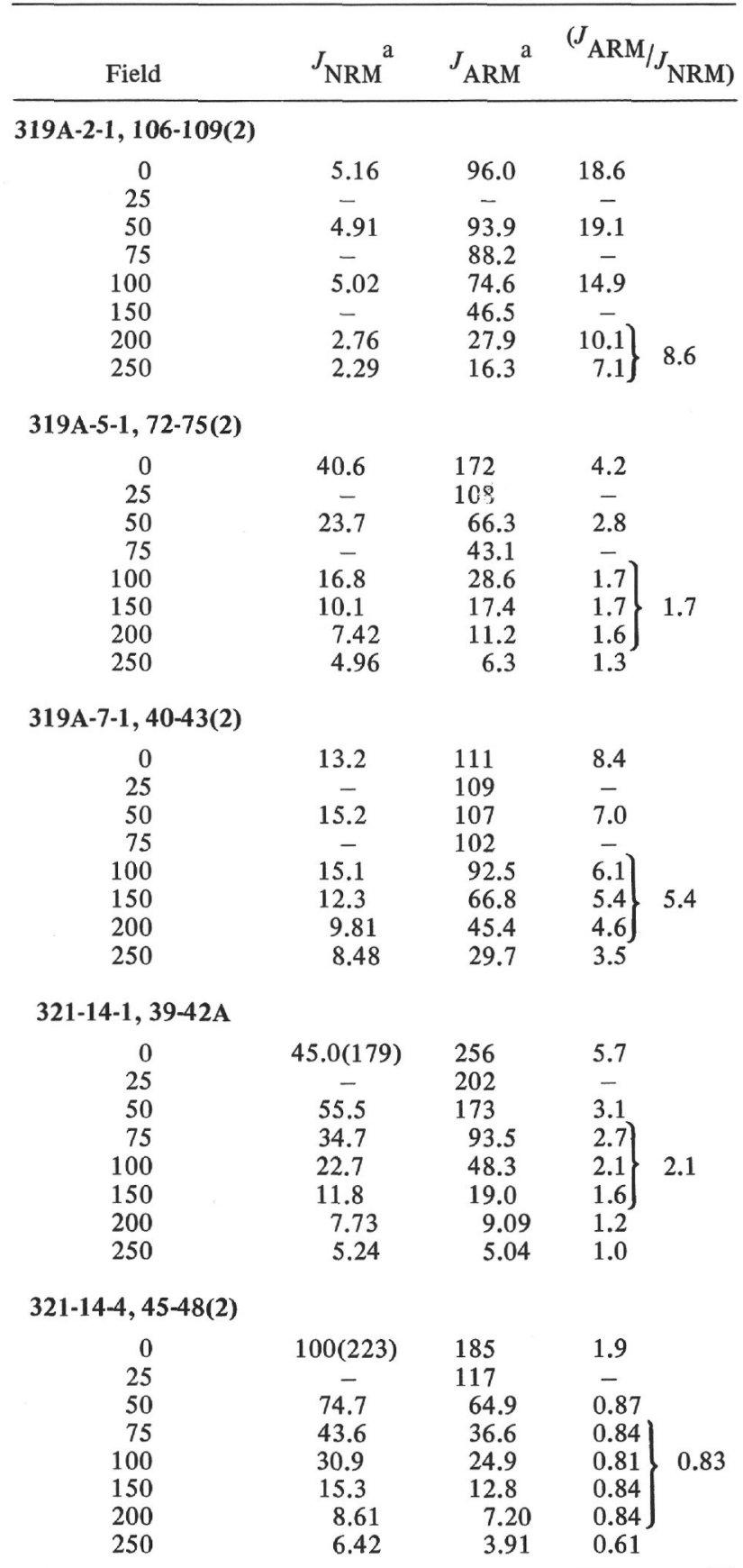

${ }^{\mathrm{a}}$ All magnetic moments are in units of $10^{-4} \mathrm{emu} \mathrm{cm}^{-3}$

the last sample than for the first three from this site. Clearly, this is contrary to the expectation of in situ acquisition of $J_{\text {soft }}$ in the present earth's field and is likely to be the result of accidental inversion of one sample. If this is the case, $J_{\text {soft }}$ for the Site 157 basalts is likely to have a uniform steep downwards inclination, in contrast to the steep upwards inclination for the Site 319 basalts.

We next consider the bearing of the additional information on $J_{\text {soft }}$ for the Site 319 and 321 basalts on the problem of original TRM polarity determination. At both sites, $J_{\text {soft }}$ approximately opposes $J_{\text {hard }}$, but the inclinations of $J_{\text {soft }}$ at the two sites are very different. At Site 319 the inclination is close to -90 (vertically upwards), and at Site 321 the average for two samples is +28 . Review of the collected properties of $J_{\text {soft }}$ leads to the result that some of the properties favor their interpretation as viscous moments acquired in the present field while others clearly do not. That both $J_{\text {soft }}$ and $J_{\text {hard }}$ are close to the same vertical plane is consistent with them both being acquired in an axially dipolar geomagnetic field. Small divergences from the common plane can reasonably be attributed to sampling of different parts of secular variation cycles. However, within the common plane, the inclinations of $J_{\text {soft }}$ are very far from the inclinations of the present field at both sites $\left(-90^{\circ}\right.$ compared with -25 presently at Site 319 and +28 compared with -23 at Site 321 ). Following a suggestion by Rainbow et al. (1972), explanation of these apparently conflicting results may be obtained from the information given in the operations reports (this volume) for the sites. The basement section at Site 319 was drilled using the normal all-steel bottom-hole assembly. In contrast, at Site 321 the lowermost drill collar of the bottom-hole assembly was made of monel metal, a nonmagnetic alloy. From this information we suggest that $J_{\text {soft }}$ is itself a resultant of two components, an axial component acquired during the drilling process and an in situ component acquired in the present normal polarity earth's field over the last $7 \times 10^{5} \mathrm{yr}$. This model is consistent with both $J_{\text {soft }}$ and $J_{\text {hard }}$ lying close to the same vertical plane. That is, the drilling induced component is axial and therefore cannot affect the azimuthal component of the $J_{\text {soft }}$ in the in situ basalts. Again, the approximately axial $J_{\text {soft }}$ for the Site 319 basalts fits well with the concept of a strong drilling-induced component arising from the use of an all-steel bottom-hole assembly. At Site 321, the use of a less magnetic bottomhole assembly suggests that $J_{\text {soft }}$ might still show a significant in situ component. If this interpretation is correct, the opposition of the azimuthal components of $J_{\text {soft }}$ and $J_{\text {hard }}$ for the Site 321 basalts implies that $J_{\text {hard }}$ has reverse polarity. That is, the basalts of Unit 3 at Site 321 were extruded and magnetized during a reverse geomagnetic polarity epoch.

The results of this analysis of the soft components of undemagnetized NRMs have important conclusions other than the determination of original TRM polarity. In particular:

1) It is likely that very large in situ soft components occur in the NRM of coarser grained submarine basalts. Since, in the Nazca plate at least, the magnetization of this type of material dominates the overall magnetization of the sections drilled, determination of the in situ soft magnetization is very important.

2) Determination of in situ soft components is complicated by the partial, or nearly complete, modification of soft components during the drilling process. Since the use of a monel metal lowermost drill collar reduces remagnetization during drilling, the use of monel drill collars and core barrels is recommended for all future basement drilling. This recommendation should be 

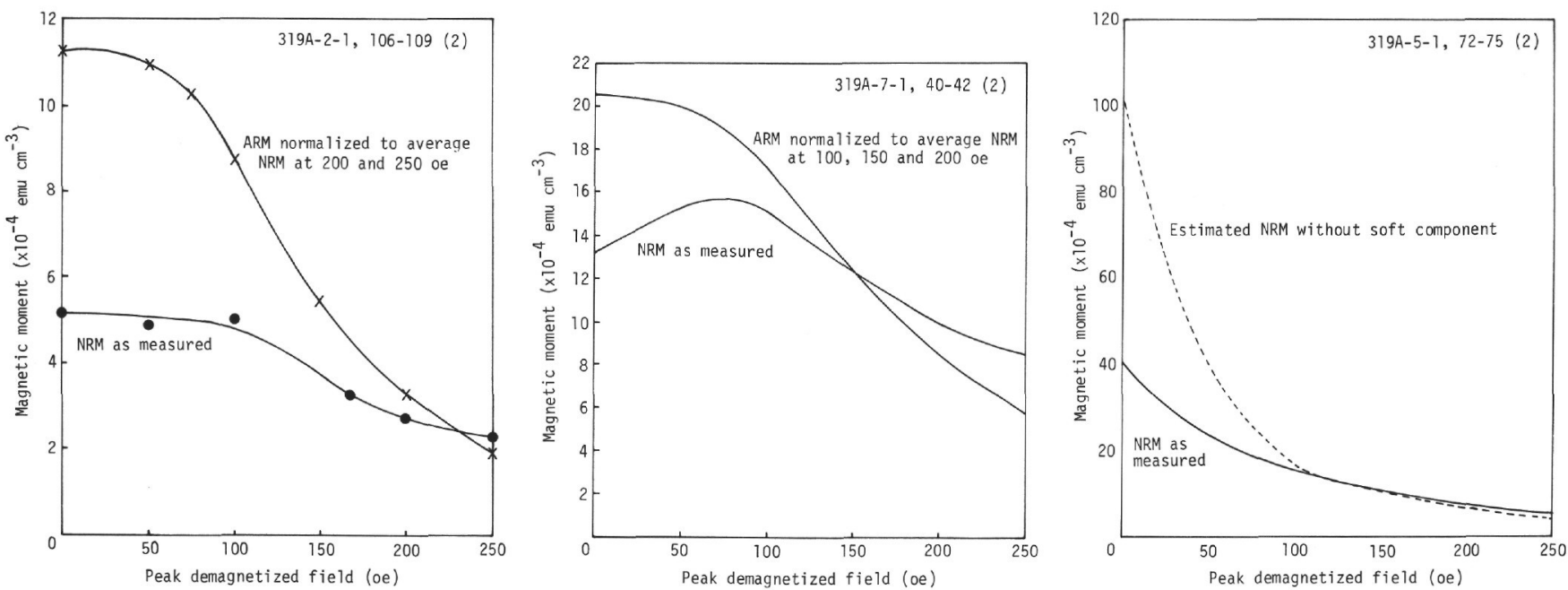

Figure 7. Site 319. Alternating field demagnetization curves for the NRM of selected samples, with ARM curves fitted to the NRM curves at the indicated field values.

TABLE 6

Errors in Using the Simple Model to Estimate the Soft Component in Undemagnetized NRMs

\begin{tabular}{|c|c|c|c|c|}
\hline $\begin{array}{c}\text { Sample } \\
\text { (Interval in } \mathrm{cm})\end{array}$ & $\begin{array}{c}J_{\text {soft }} \text { From the } \\
\text { Simple Model (1) }\end{array}$ & $\begin{array}{c}J_{\text {soft }} \text { From } \\
\text { ARM/NRM } \\
\text { Comparisons (2) }\end{array}$ & Error $\left(\frac{1-2}{2}\right) \%$ & $\begin{array}{l}\text { Anticipated } \\
\text { Error From the } \\
\text { Construction } \\
\text { Shown in } \\
\text { Figure } 9\end{array}$ \\
\hline $319 A-2-1,106-109(2)$ & $\begin{array}{l}9.4 \times 10^{-4} \mathrm{emu} \mathrm{cm}^{-3} \\
\text { at } 90^{\circ} \text { inclination }\end{array}$ & 8.8 at -88 & $\begin{array}{c}+7 \% \text { (simple } \\
\text { model value } \\
\text { too high) }\end{array}$ & $\begin{array}{l}+9 \% \text { (simple } \\
\text { model value } \\
\text { too high) }\end{array}$ \\
\hline $319 A-5-1,72-75(2)$ & 79.4 at $-90^{\circ}$ & 105 at -83 & $\begin{array}{l}-24 \% \text { (simple } \\
\text { model value } \\
\text { too low) }\end{array}$ & $\begin{array}{c}-21 \% \text { (simple } \\
\text { model value } \\
\text { too low) }\end{array}$ \\
\hline $319-7-1,40-43(2)$ & 5.1 at $-90^{\circ}$ & 8.5 at -73 & $-40 \%$ & $-54 \%$ \\
\hline Average error & & & $-19 \%$ & $-22 \%$ \\
\hline
\end{tabular}

followed even if it is not planned to take oriented cores (the original purpose for the monel metal bottom-hole assembly components). In this way the soft NRM components of in situ basalts may be preserved for measurement without overprinting by magnetic fields associated with all-steel bottom-hole assemblies.

\section{In Situ Basalt Magnetization}

In this section we approach the problem of assessing the total magnetization of the basement sections recovered. This is a geophysical parameter of great importance, both for implications regarding the geologic and geomagnetic history of the areas and for the correct modeling of sources of oceanic linear magnetic anomaly patterns.

The net magnetization of a sequence of rocks will be the vector sum of contributions from three types of magnetizations: stable natural remanent magnetization (NRM), viscous remanent magnetization (VRM), and induced magnetization. For basalts, VRM and induced magnetization can be taken as having the direction of the present field at the site. However, stable NRM direction can vary widely, and this must be determined by measurement. The information listed in both preceding sections can be used to obtain the contributions from NRM and induced magnetization. VRM has not been determined for the samples described in this chapter. Lowrie (this volume) has determined VRM for other Leg 34 basalts: for the unaltered massive basalts very large in situ VRMs are indicated (Ade-Hall and Johnson, Review of Magnetic Properties of Basalts and Sediments, this volume).

Complete NRM determination requires both direction and intensity values. For the basalts from Sites 157, 319 , and 320 only intensity and NRM inclination are known with certainty. For some Site 321 NRMs, declination may be estimated from the properties of soft components. Reverse magnetization, with declination close to $180^{\circ}$ is indicated. As for other submarine basalts (see Fox and Opdyke, 1973, for a summary of references), the ratio of NRM to induced magnetization $(Q$ ratio) is high for all the Leg 34 basalts (Tables 1 and $8)$.

In Table $8, Q$ has been estimated in several ways. For Site 319 basalts minimum and maximum values are given, corresponding to measured NRM values and 

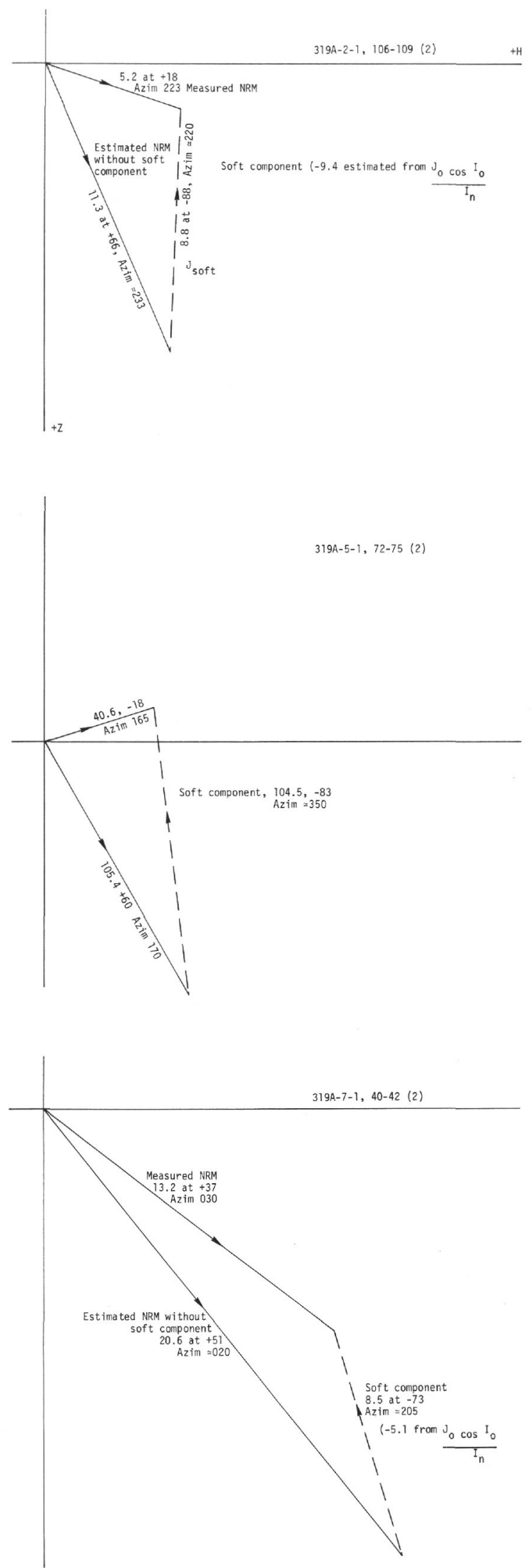

Figure 8. Site 319. Vector plotting method to determine the magnitude and inclination of $\mathrm{J}_{\text {soft }}$ for selected samples.

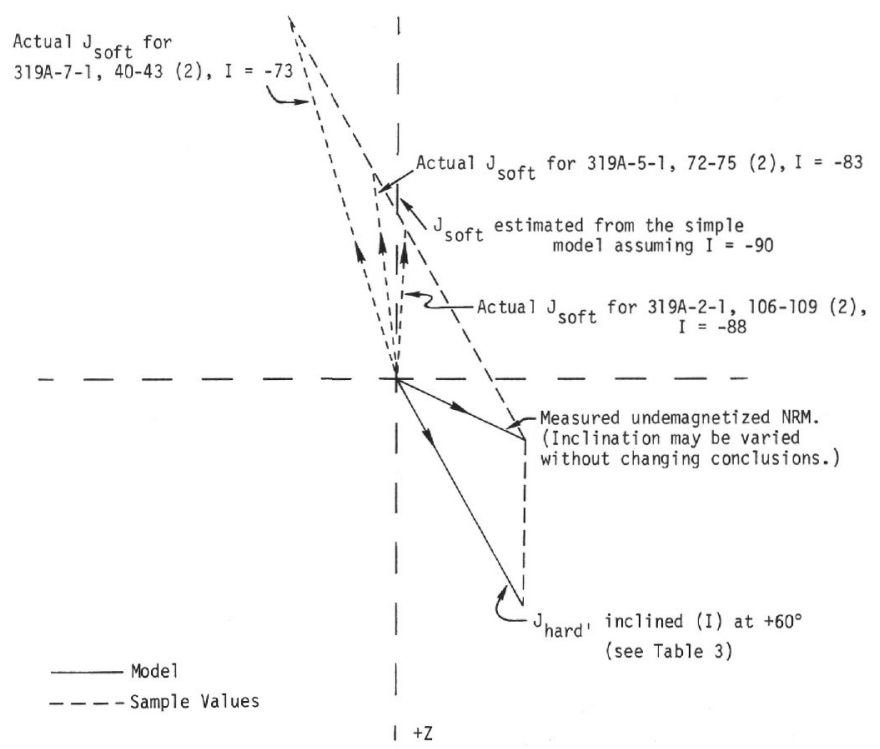

Figure 9. Illustration of errors in estimating $\mathrm{J}_{\text {soft }}$ from the simple model, where $\mathrm{J}_{\text {soft }}$ is assumed to be oriented vertically upwards.

hypothetical NRM values for single-component NRM with the inclination of $J_{\text {hard }}$. Both values have been given in view of the uncertainty regarding the magnitude and direction of $J_{\text {soft }}$ in the in situ basalts at this site. A similar choice can be made for the Site 321 basalts, but it is assumed here that at least the major part of the measured $J_{\text {soft }}$ represents in situ soft magnetization. For Site 320 basalts, where soft components are small or absent, the measured NRMs equate closely with the in situ values. In any event, the overall high average $Q$ ratio of 14 is probably a minimum value. While the average contribution of induced magnetization at each site varies from $3 \%$ to $17 \%$ of the remanent magnetization, it is clear that if the measured remanence represents in situ remanence then induced magnetization is with one exception a minor contribution to total magnetization. That $Q$ is, with one exception, higher than unity is a result of the general increase of remanence with increase in susceptibility (Figure 12). This relationship is analyzed more fully in Ade-Hall et al., Rock Magnetism of Basalts (this volume).

In assessing the total magnetization of the two basement sections, allowance must be made for the small and irregular recovery of material. Since massive basalts recovered well at both Sites 319 and 321, and finegrained material poorly at all sites, we have weighted the site average NRM intensities for the differential recovery (Table 9). This has been done by calculating the average magnetization over 10-meter intervals for Sites 319 and 320 and 1-meter intervals for Site 321. The difference in average intensities is greatest for Site 319 where a single 20-meter thickness of massive basalts occurs within a sequence of 60 meters otherwise consisting of pillows and other fine-grained material.

We note that the longest basement sequence, at Site 319 , has a weighted average NRM intensity of only 17.4 $\times 10^{-4} \mathrm{emu} \mathrm{cm}^{-3}, 27 \%$ lower than the unweighted average of the measured NRM values. This value is lower 

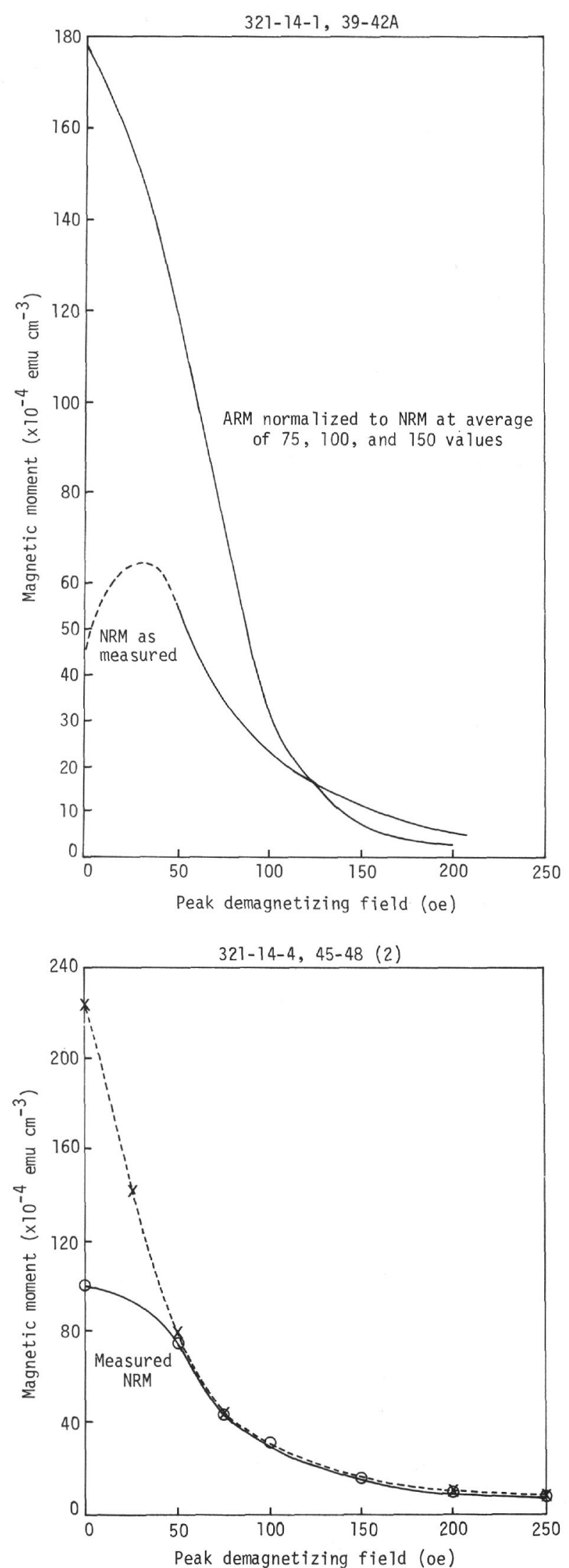

Figure 10. Site 321. Alternating field demagnetization curves for the NRM of selected samples with ARM curves fitted to the NRM curves at the indicated field values. than would be anticipated for the location of the site and extrapolated basement age (e.g., Talwani et al., 1971). Clearly, a 60 -meter basement section containing one 20 meter massive section (Figure 13) is unlikely to be representative of the $1.5-2 \mathrm{~km}$ thick layer 2 ; for example, a greater proportion of massive material at depth would raise the average NRM intensity of the section. The correlation of NRM intensity with basalt grain size observed at Site 319 also applies to the basalts from Sites 320,157 , and 321 and explains the relatively low average NRM of the former and the high average NRM of the latter two. Only fine-grained, weakly magnetized pillow fragments were recovered at Site 320 , while at Site 321 the short basement section is dominated by a massive coarse-grained unit. The Site 157 basalts examined are all coarse grained. A thorough analysis of the relationship between NRM intensity, grain size, and alteration state is described in Ade-Hall et al., Rock Magnetism of Basalts (this volume).

\section{SUMMARY}

Here we summarize the results and conclusions made in the preceding sections of this chapter. An overall discussion of the magnetic results from the Leg 34 basalts is given in Ade-Hall and Johnson, Review of Magnetic Properties of Basalts and Sediments (this volume).

The feasibility of shipboard paleomagnetic work was confirmed during Leg 34.

Alternating field cleaned basalt NRM inclinations are consistent within each recognized cooling unit. The short recovered basement sections from the four Nazca plate sites each represent one or, at the most, two time units and as such do not give sufficient information to find the representative geomagnetic field at the time of volcanic activity. In turn this implies that motions of the Nazca and other plates, estimated from the basaltic paleomagnetic inclinations, may have large and unknown uncertainties associated with them, as is shown by a comparison of the NRM inclinations for basalts and overlying sediments, especially for Site 319 .

The magnetization of the coarser grained basalts from flow interiors, recovered at Sites 157, 319, and 321, is typically much stronger than the NRM intensity of pillow fragments and is characterized by moments consisting of soft and hard components with different inclinations but lying within or close to the same vertical plane. At Sites 319 and 321 the soft components are consistently oriented at each site and oppose the sense of the hard components. At Site 157 the soft components of different samples have opposing senses suggesting that one of the samples has been inverted accidentally. At Site 319 the soft components are approximately vertically oriented upwards while at Site 321 they have shallow downwards inclination. The differences in the orientation of the soft components at the two sites is thought to be associated with the different types of bottom-hole assemblies used during drilling. The soft components at Site 321 are likely to be relatively little perturbed from their in situ nature as a nonmagnetic monel metal lowermost drill collar and core barrel was used in drilling at this site. If this interpretation is correct, the opposed soft and hard NRM components of Unit 3 at Site 321 imply a soft normal viscous component, acquired during the 


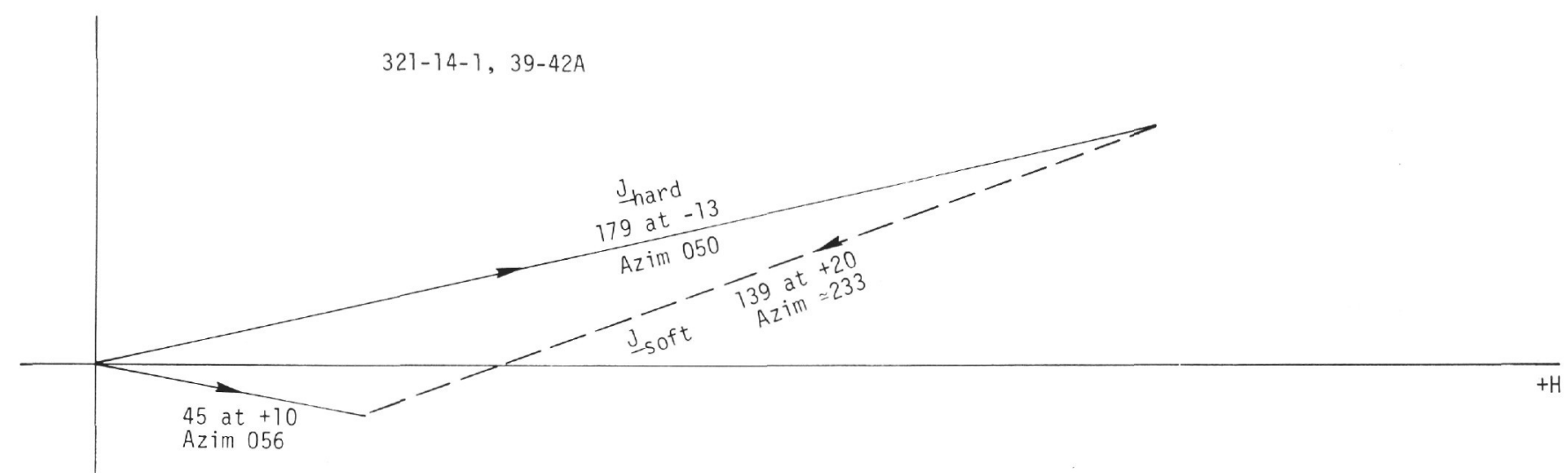

Measured undemagnetized NRM

$+\underline{Z}$

$321-74-4,45-48$ (2)

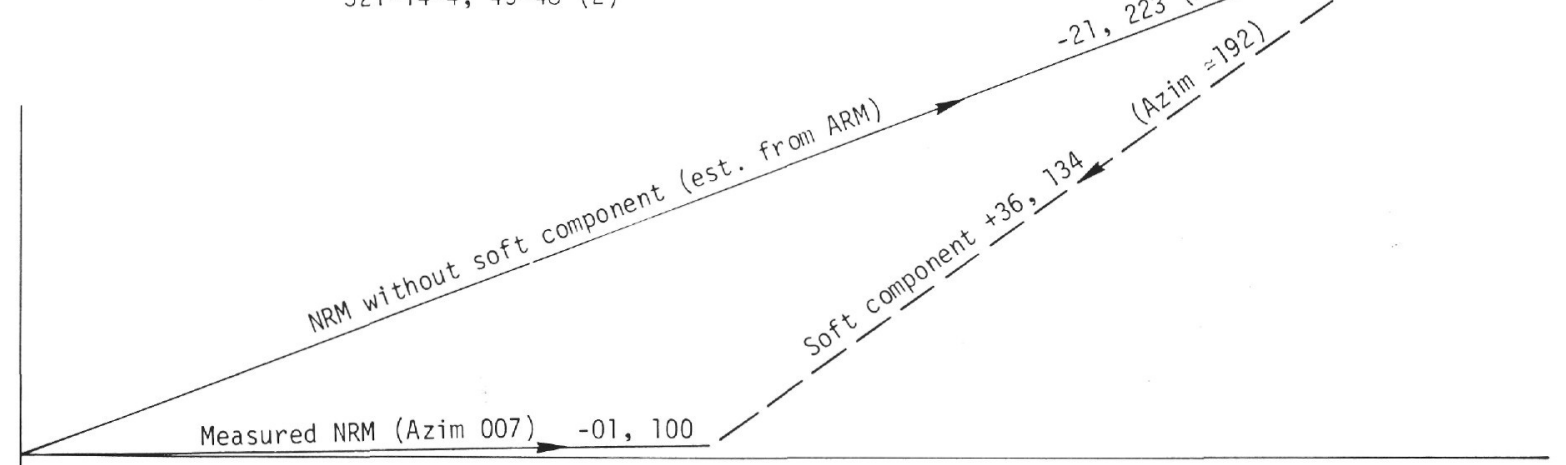

Figure 11. Site 321. Vector plotting method to determine the magnitude and inclination of $J_{\text {soft }}$ for selected samples.

TABLE 7

$J_{\text {soft }}$ and $J_{\text {hard }}$ for Two Site 321 Basalts

\begin{tabular}{cccc|ccc|cccc}
\hline & \multicolumn{3}{c|}{ Undemagnetized } & \multicolumn{3}{c|}{} & \multicolumn{4}{c}{$J_{\text {hard }}$} \\
\cline { 2 - 11 } Sample & $J^{\mathrm{a}}$ & $\phi^{\mathrm{b}}$ & $I^{\mathrm{c}}$ & $J^{\mathrm{a}}$ & $\phi^{\mathrm{b}}$ & $I^{\mathrm{c}}$ & $J^{\mathrm{a}}$ & $\phi^{\mathrm{b}}$ & $I^{\mathrm{c}}$ \\
\hline $321-14-1,39-42 \mathrm{~cm}$ & 45.0 & 056 & +10 & 139 & 223 & +20 & 179 & 050 & -13 \\
$321-14-4,45-48 \mathrm{~cm}(2)$ & 100 & 007 & -01 & 134 & 192 & +36 & 223 & 018 & -21 \\
\hline
\end{tabular}

$\mathrm{a}_{\mathrm{emu} \mathrm{cm}}-3 \times 10^{4}$.

${ }^{b}$ Declination in degrees measured from the reference line of unknown absolute azimuth.

${ }^{\mathrm{c}}$ Inclination in degrees. 
TABLE 8

Range and Average Induced Magnetization Values of Leg 34 Basalts

\begin{tabular}{cccc}
\hline Site & $\begin{array}{c}Q \pm \text { Standard } \\
\text { Deviation of } \\
\text { the Mean }\end{array}$ & Range & $\begin{array}{c}\text { Average } \\
\text { Induced } \\
\text { Magnetization } \\
\text { as Percentage } \\
\text { of NRM }\end{array}$ \\
\hline 157 & $6 \pm 1$ & $4-8$ & 17 \\
319 & $12 \pm 2(16 \pm 3)^{\mathrm{a}}$ & $2-19(4-41)^{\mathrm{a}}$ & 8 \\
320 & $39 \pm 7$ & $19-56$ & 3 \\
321 & $6 \pm 1$ & $1-19$ & 17 \\
Overall average 14 & &
\end{tabular}

${ }^{\mathrm{a}}$ Calculated for equivalent single component NRMs.

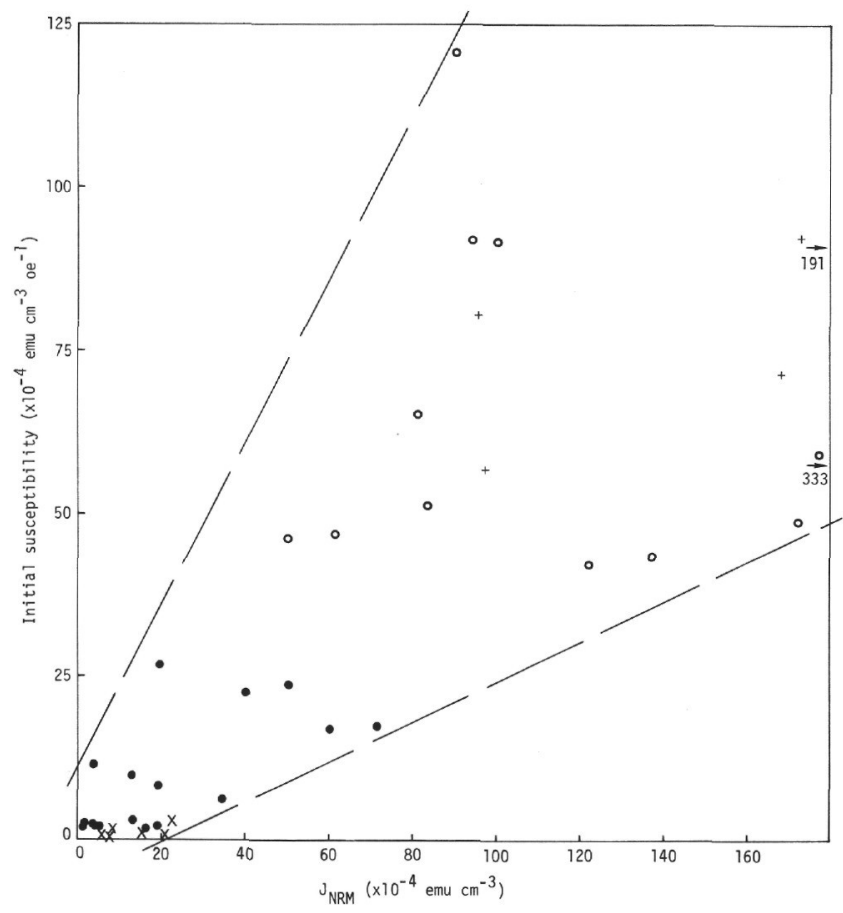

Figure 12. Relationship between initial susceptibility and NRM intensity.

Brunhes normal epoch, and an original cooling reverse polarity hard magnetization. A new method for the polarity determination of partly oriented drill core basalts is evident here, but needs further testing before its reliability is assured.

The remanent magnetization of all the Leg 34 basalts dominates the induced magnetization. However, the in situ magnetization of the unaltered coarse-grained basalts at Sites 319 and 321 must be dominated by a viscous component, presumably aligned in the direction of the present geomagnetic field (Ade-Hall and Johnson, Review of Magnetic Properties of Basalts and Sediments, this volume).

An important technical recommendation arising from this paleomagnetic study is that monel metal lowermost drill collars and core barrels should always be used in basement drilling, even if it is not planned to take oriented cores. In this way, the geophysically important soft NRM components of the in situ basalts may be
TABLE 9

Site Average NRM Intensity of Leg 34 Basalts

\begin{tabular}{llc}
\hline Site & & $\begin{array}{c}\text { Site Average } \\
\text { NRM Intensity } \\
\left(\times 10^{-4} \text { emu cm }\right.\end{array}$ \\
\hline 157 & (1) Average of all NRM values & $138 \pm 24$ \\
319 & $\begin{array}{l}\text { (1) Average of all NRM values } \\
\text { (2) Weighted for differential }\end{array}$ & $23.8 \pm 5.7$ \\
& recovery of fine and coarse \\
& basalts by averaging over & \\
320 & (1) Average of all NRM values & $13.4 \pm 5.9$ \\
321 & (2) (10-m intervals $)$ & $13.2 \pm 7.6$ \\
& (1) Average of all NRM values & $103 \pm 23$ \\
& (2) Average over 1-m intervals & $96 \pm 23$ \\
\hline
\end{tabular}
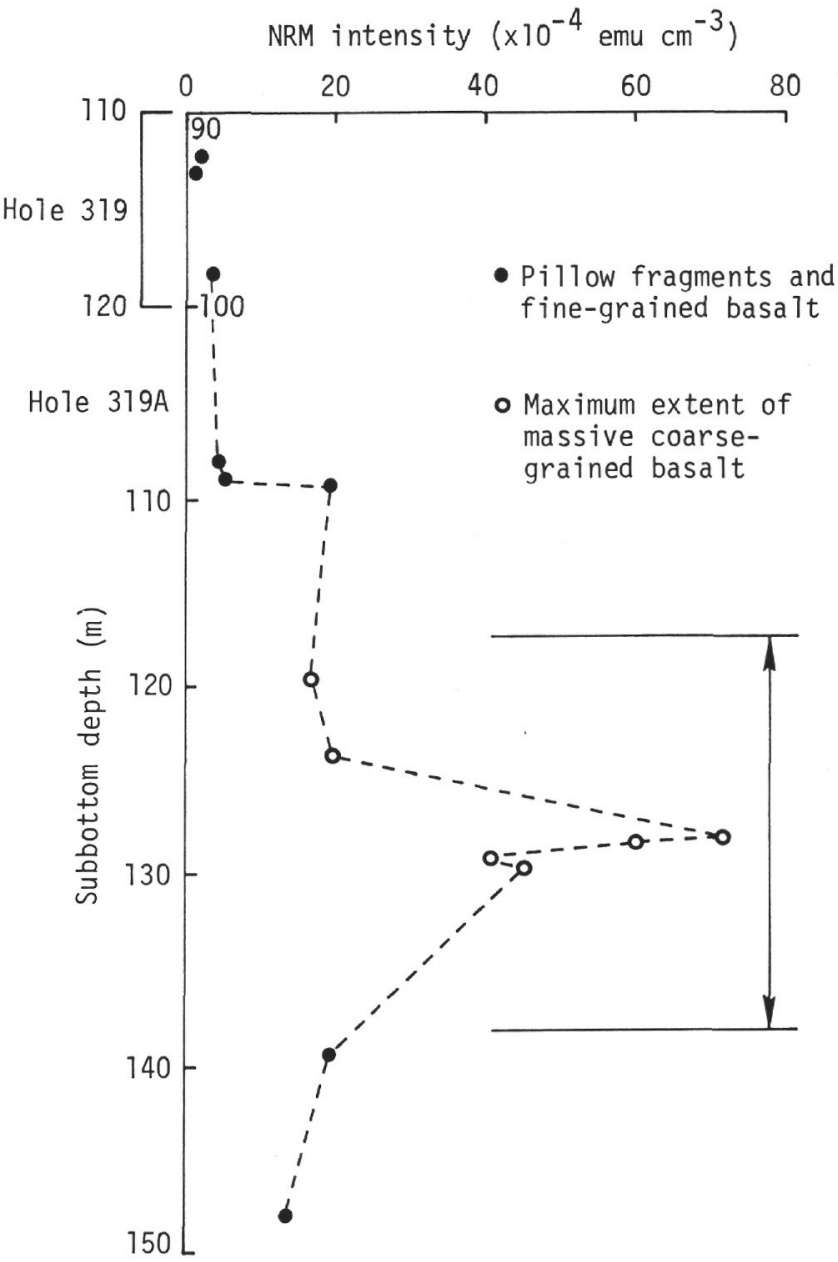

Figure 13. NRM intensity and depth for basalt samples from Site 319.

preserved for measurement without overprinting by the magnetic fields associated with all-steel bottom-hole assemblies.

\section{ACKNOWLEDGMENTS}

We should like to thank the shipboard scientists and technical staff on Leg 34 for their careful help in, respectively, sampling the recovered basalts and setting up and maintaining the shipboard paleomagnetic laboratory. 
Captain Spears, the ship's crew, and the drilling team worked very hard to satisfy the scientific aims of the leg. Monika Michaelis typed the manuscript and the DSDP drafting staff was responsible for the figures. Paul Johnson would like to thank Dalhousie University for a Postdoctoral Fellowship during which the Leg 34 studies were carried out. Patrick Ryall assisted the authors considerably by critically reading the first draft of this chapter.

\section{REFERENCES}

Ade-Hall, J.M., Palmer, H.C., and Hubbard, T.P., 1971. The magnetic and opaque petrological response of basalts to regional hydrothermal alteration: Geophys. J., v. 24, p. 137-174.

Ade-Hall, J.M., Reynolds, P.H., Dagley, P., Mussett, A.E., Hubbard, T.P., and Klitzsch, E., 1974. Geophysical Studies of North African Cenozoic volcanic areas. I: Haruj Assuad, Libya: Canadian J. Earth Sci., v. 11, p. 998-1006.

Crandell, D.R., Mulleneaux, D.R., and Rubin, M., 1975. Mount St. Helens volcano: Recent and future behavior: Science, v. 187, p. 438-441.
Melson, W., W., Aumento, F., et al., 1975. Deep Sea Drilling Project Leg 37-the volcanic layer: Geotimes, v. 19, p. 1618.

Fox, P.J. and Opdyke, N.D., 1973. Geology of the oceanic crust: Magnetic properties of oceanic rocks: J. Geoph. Res., v. 78, p. 5139-5154.

Levi, S., 1973. Comparison of some ARM and TRM properties in magnetites: Am. Geoph. Union Trans., v. 54, p. 1071.

Rainbow, R.R., Fuller, M., and Schmidt, V.A., 1972. Paleomagnetic orientation of borehole samples: Am. Geoph. Union Trans., v. 63, p. 355.

Rimbert, F., 1959. Contribution á l'etude de l'action de champs alternatifs sur les aimentations remanentes des roches: Rev. Inst. Fr. Petrole. Ann. Combus. Liquides, v. 14, p. 1-75.

Talwani, M., Windisch, C.C., and Langseth, M.G., 1971. Reykjanes Ridge Crest: A detailed geophysical study: J. Geoph. Res., v. 76, p. 473-517.

Wilson, R.L., 1970. Paleomagnetic stratigraphy of Tertiary lavas from Northern Ireland: Geophys. J., v. 20, p. 1-10. 